\title{
13 „Hurra wir zwingen das Glück“: Autobiografische Erlebnisberichte junger Erwachsener aus dem „NS-Arbeitsdienst“
}

Um möglichst vielfältige Subjektivierungsdiskurse zur Analyse einer Politik der ,Glückskulturen' untersuchen zu können, ist es wichtig, neben hegemonialen Diskursen (top down) auch Einzelstimmen von Zeitzeug*innen (bottom up) aus dem nationalsozialistischen Alltagsleben zu Wort kommen zu lassen. Aus diesem Grund werden im vorliegenden Kapitel exemplarisch die autobiografischen Erlebnisberichte von Lisa Tasche und Gustav Faber aus dem freiwilligen „NSArbeitsdienst“" untersucht. $^{1}$ Die Analyse kann aufzeigen, wie Autor*innen von autobiografischen Erlebnisberichten im Rahmen der NS-Arbeitspolitik emotionspolitische Erziehungsaufgaben übernahmen. Ähnlich den Glücksratgeberautor^innen deuteten die jungen Autor`innen die individuelle und leistungsorientierte Selbstoptimierungskultur der Weimarer Republik im Sinne der „rassenhygienischen“ Arbeitsmoral um und entwarfen das Ideal einer Politik der nationalsozialistischen ,Glückskulturen‘. Begriffe wie „Glück“, „Freude“, „Kraft“, „Wille“, „Leistung“, „Arbeit“, „Ehre“, „Vertrauen“, „Opfer“, „Dienst“ und „sittliche[r] Ernst“"2 wurden zu Schlagwörtern ihrer subjektiven Beschreibungen der nationalsozialistischen Lebensführung. Die Autobiograf*innen bewarben das Leben im „NS-Arbeitsdienstlager“ als einen emotionspolitischen Erlebnisraum, in welchem individuelle Selbsterziehungspraktiken die Entfaltung einer „Kraft durch Freude“ bewirken könnten. Sie versprachen zudem ihrer Leserschaft, bzw. den „Kameradinnen“ und „Werksoldaten“3, soziale Aufstiegsmöglichkeiten innerhalb der „Volksgemeinschaft“, wie es sie in der kapitalistisch-bürgerlich dominierten Weltanschauung der Weimarer Republik niemals gegeben hätte. ${ }^{4}$ Die jungen Autor ${ }^{\star}$ innen richteten sich folglich in erster Linie an ein gleichaltriges Zielpublikum von 16- bis 25-Jährigen, die am Anfang ihrer beruflichen Laufbahn standen. Von ihrer freiwilligen Partizipation hing in den ersten Aufbaujahren die längerfristige Legitimation und Stabilisierung der „NS-Volksgemeinschaft“ ab. Sie verkörperten (wortwörtlich) die Zukunft der „rassenreinen“ NS-Gesellschaftsutopie, sofern sich die jungen Menschen autosuggestiv von der moralischen Rechtschaffenheit der NS-Arbeitsmoral selbst überzeugten.

1 Vgl. Tasche 1935, vgl. Faber 1934.

2 Vgl. Faber 1934, [Klappentext].

3 Ebd., 143.

4 Mehr zur Frage „Wie bürgerlich war der Nationalsozialismus?“ vgl. Frei 2018.

○ OpenAccess. () 2021 Isabelle Haffter, publiziert von De Gruyter. (cc))BY-NC-ND Dieses Werk ist lizenziert unter einer Creative Commons Namensnennung - Nicht kommerziell - Keine Bearbeitung 4.0 International Lizenz. https://doi.org/10.1515/9783110661439-013 
Für den freiwilligen Einsatz im „NS-Arbeitsdienst“ warben die jungen Autor^innen nicht vorrangig mit einer aggressiv-repressiven oder antisemitischen Propagandastrategie. Ihre Erlebnisberichte beschreiben in erster Linie affirmative Gefühle. Zentrales Element ihrer Berichte ist die individuelle Wahrnehmung ihrer psychisch und physisch wahrgenommenen Glückserfahrungen im „NS-Arbeitsdienst“. Diese Glücksgefühle glaubten Tasche und Faber während der Ausübung von Hof- und Heimarbeit oder bei Bau- und Handwerksarbeiten als sinnstiftendes Gemeinschaftserlebnis verspürt $\mathrm{zu}$ haben. Die angeblich authentisch aus dem Leben der jungen Erwachsenen gegriffenen Erfahrungen sollten die Leserschaft von der Wahrhaftigkeit ihrer Gefühle und der moralischen Rechtschaffenheit ihres Handelns überzeugen.

Was war der emotionspolitische Zweck ihrer Berichte? Das übergeordnete Ziel dieser Publikationen war eine emotionspolitische Mobilisierung. In wissenshistorischer Kontinuität zur Ratgeberpraktik musste die ideologisch noch unentschlossene Leserschaft von der NS-Arbeitsmoral „Kraft durch Freude“ restlos überzeugt werden. Selbstdisziplinarische Handlungsweisen und autosuggestive Willenspraktiken, die von den Autobiograf*innen ausführlich beschrieben wurden, sollten die ideologisch überhöhten Glückspraktiken für die Leser^innen nachvollziehbar machen und sie zur Nachahmung anregen. Passend lautete der Titel des Erlebnisromans von Lisa Tasche „Hurra wir zwingen das Glück“.

Die folgende Untersuchung will in einem Vergleich die unterschiedlichen Geschlechterperspektiven der Autor^innen auf den jeweils weiblichen oder männlichen Einsatz im freiwilligen „NS-Arbeitsdienst“ analysieren. Dabei sollen Gemeinsamkeiten und Unterschiede ihrer emotionspolitischen Erfahrungen im vom NS-Regime geschlechterstereotypisierten „NS-Arbeitsdienst“ herausgearbeitet werden. Die übergeordnete Frage lautet: Mit welchem arbeitspsychologischen Glückswissen, welchen sprachlichen Mitteln, Metaphern, Semantiken, Erfahrungen, Begegnungen und Gefühlsbeschreibungen versuchten die jungen Autor^innen, die Leserschaft von ihren Glückserlebnissen im „NS-Arbeitsdienst“ zu überzeugen?

Für eine kritische Quellenanalyse von autobiografischen Erlebnisberichten aus der NS-Zeit muss zunächst der historische Entstehungskontext dieser Publikationen berücksichtigt werden. Gefragt wird, unter welchen rechtlichen, ökonomischen und publizistischen Rahmenbedingungen die Erlebnisromane 1934 und 1935 veröffentlicht wurden. 


\subsection{Der „Verlag für Kulturpolitik“ und die NS-Literaturpolitik einer „volkshaften Dichtung“}

Seit 1933 waren der deutsche Buchhandel und das Verlagswesen ,gleichgeschaltet“. Der Erlass der „Reichskulturkammergesetze“ im Herbst 1933 hatte für die Kultur- und Wirtschaftsbetriebe weitreichende Folgen. Rund 100 Verlage wurden allein 1933 verboten, „arisiert“ oder geschlossen. Jüdische Unternehmer^innen oder Verlagshäuser, die Literatur mit religiösen, sozialistischen oder allgemein „staatsfeindlichen“ Inhalten vertrieben, wurden zur Schließung oder Emigration gezwungen. ${ }^{5}$

Die Erlebnisberichte von Lisa Tasche und Gustav Faber sind 1934 und 1935 im Berliner „Verlag für Kulturpolitik“ erschienen. Dieser Verlag unterstand zu diesem Zeitpunkt laut Handelsregisterakte Nr. 57699 offiziell nicht der NSDAP, obschon der Verlagsname darauf schließen lassen könnte. ${ }^{6}$ Der „Verlag für Kulturpolitik“ war am 18. Dezember 1928 als GmbH vom Geschäftsführer Karl Friedrich Nowak (1882-1932), einem österreichischen Schriftsteller und Journalisten, gegründet worden. Der Verlag hatte sich auf die Veröffentlichung der Memoiren von Militärangehörigen und politischen Machthabern spezialisiert. ${ }^{7}$ Nach seinem Tod am 17. Dezember 1932 übernahm seine Frau, Thea Nowak, eine Verlegerin und Übersetzerin, die Geschäftsleitung. Seit Dezember 1933 war der Theaterintendant Willy Stuhlfeld (1879-?) der Geschäftsführer des „Verlags für Kulturpolitik“. ${ }^{8}$ Nach einigen Wechseln in der Geschäftsleitung kaufte Otto Schaffer, „Mitglied der Reichsschrifttumskammer und der Reichskulturkammer“, dem damaligen Geschäftsführer Karl Robert Leopold Hoese das Verlagshaus inklusive aller „Verlagsrechte[...], Buchwerte[...]“ und Inventarien für 85.000.- RM ab. Zu diesem Zeitpunkt umfasste das Verlagsprogramm neben der „Herausgabe von Romanen (Unterhaltungslektüre)“ auch Biografien historischer Persönlichkeiten. Der Buchvertrieb wurde über die Firma Fleischer in Leipzig und Neumann/Bentzel in Berlin abgewickelt. Der Umsatz betrug 1938 über 100.000.- RM. ${ }^{9}$ Mit Blick auf die

5 Vgl. Saur 2013, 7. Mehr zur NS-Literaturpolitik und Literatur im Nationalsozialismus vgl. Wulf 1983, Paucker 1984, Kamenetsky 1986, Ketelsen 1994, Hartung 2001, Graeb-Könneker 2001, Tavernaro 2004, Barbian 1995, Barbian 2008, Barbian 2013.

6 Vgl. A Rep. 342-02 Amtsgericht Charlottenburg - Handelsregister, Nr. 57699, Verlag für Kulturpolitik GmBH, 1928-1939, Landesarchiv Berlin.

7 Nowaks Publikationen vgl. u.a. Nowak 1926.

8 Vgl. A Rep. 342-02 Amtsgericht Charlottenburg - Handelsregister, Nr. 57699, Verlag für Kulturpolitik G.m.b.H., 1928-1939, Landesarchiv Berlin. Zu Nowak vgl. Institut für Neuzeit- und Zeitgeschichtsforschung 1976. Vgl. Stuhlfeld 1940.

9 Vgl. Schreiben an das Amtsgericht Charlottenburg betrifft: „Verlag für Kulturpolitik Otto Schaffer (Uebernahme des Verlages für Kulturpolitik G.m.b.H.), Berlin, 12.05.1939, unterzeichnet 
im Katalog der „Deutschen Nationalbibliothek“ aufgeführten Veröffentlichungen führte Schaffer den Verlag in thematischer Nähe zu Karl Friedrich Nowaks publizistischem Konzept weiter.

Angesichts dieser Kontinuität des Verlagsprogramms seit 1928 stellt sich die Frage, welche machtpolitischen Mechanismen die NSDAP auf die deutsche Verlagslandschaft ausübte. Alle Verlage wurden strengstens kontrolliert. Viele Publikationen erhielten weder Veröffentlichungsgenehmigungen noch Papierzulieferungen. Wurden 1932 noch über 32.000 Titel publiziert, sank die Zahl 1934 auf 24.000 Neuerscheinungen. Der „Verlag für Kulturpolitik“ gehörte zu der großen Zahl an Verlagen (z. B. R. Piper Verlag, Metzler Verlag, Kohlhammer Verlag), die sich mehr oder weniger der „Gleichschaltung“ anpasste, indem sie 30-50\% „Naziliteratur“ neben 50-70\% für das Regime unproblematische Literatur veröffentlichte. ${ }^{10}$

Seit 1934 publizierte die „Zeitschrift für Leihbüchereien“ als ideologisches Lenkungsinstrument die von Goebbels’ „Reichsschrifttumskammer“ zusammengestellte „Grundliste für die Leihbüchereien“. ${ }^{11}$ Auf dieser Grundlage sollten die „Säuberungen“ der Buchbestände der Bibliotheken erfolgen und Ankäufe auf die propagandistische Infiltration der Leserschaft ausgerichtet werden. 1936 erschien die „Erste Grundliste für den deutschen Leihbuchhandel“, die fortan jährlich bis 1943 in der Zeitschrift „Das Buch ein Schwert des Geistes“ erschien. ${ }^{12}$ Die Zeitschrift betonte neben Theater, Film und Rundfunk die kulturpolitische Bedeutung der Literatur zur Unterhaltung, Zerstreuung und Erbauung der Moral der kriegsmüden Soldaten an der Front und der kriegsgebeutelten Bevölkerung an der „Heimatfront“. ${ }^{13}$

Im Rahmen der NS-Literaturpolitik wurde eine nationalsozialistische Belletristik gefördert. Besonderen Wert legte die NS-Literarturtheorie auf die sogenannte „Volksliteratur“, wie sie der Verleger und „Leiter des Lektorats der Reichsstelle zur Förderung des deutschen Schrifttums“ Hellmuth Langenbucher (1905 - 1980) (NSDAP-Mitglied seit 1929) wirkungsmächtig in seinem rassistischen und antisemitischen Kanon „Volkshafte Dichtung der Zeit“ (1933) entwarf. ${ }^{14}$ „Deutsche“ Schriftsteller sollten im Nationalsozialismus aus einer „völkischen“

\footnotetext{
„i.A. Grasshoff“, A Rep. 342-01 Amtsgericht Charlottenburg - Handelsregister, Nr. 44718, Verlag für Kulturpolitik Otto Schaffer, 1939-1941, Landesarchiv Berlin.

10 Vgl. Saur 2013, 8-15.

11 Vgl. Adam 2010, 33.

12 Vgl. Reichsministerium für Volksaufklärung und Propaganda, Abteilung Schrifttum 1940.

13 Vgl. Adam 2010, 28f.

14 Vgl. Langenbucher 1933. Zur Förderung der „,volkshaften Dichtung“ vgl. Barbian 2015b, 197 204.
} 
Weltanschauung das „wirkliche[...] deutsche[...] Schicksal[...]“ sowie das „Schicksal ihres Volkes“, „des deutschen Lebens und deutschen Wesens“ literarisch darstellen. ${ }^{15}$ Der NS-Literaturpolitik zufolge sollten die „Volkgenossen“ eigenhändig den Schreibstift ergreifen und ihre Eindrücke und Erlebnisse in Romanen und Dramen aus einer nationalsozialistischen „Weltanschauung“ heraus beschreiben. Einige Protagonisten, wie der Erfolgsautor Hans Zöberlein (18951964), die während der Weimarer Republik erfolglos gewesen waren, konnten sich nach der „arisierten“ „Gleichschaltung“ zu Publizisten mausern. ${ }^{16}$ Eine Folge der autodidaktischen NS-Literaturpolitik waren Abstriche in der literarischen Qualität. Mit Blick auf die von Christian Adam zusammengestellte Bestsellerliste 19331945 wird deutlich, dass bei der Leserschaft eine $\mathrm{zu}$ aggressiv auftretende ,rassenideologische“ „Blut-und-Boden“-Literatur viel weniger Anklang fand, als es sich Goebbels von seiner NS-Literaturpolitik erhofft hatte. ${ }^{17}$

Mit dieser kurzen historischen Kontextualisierung des Verlagswesens im Nationalsozialismus und der NS-Litertaturpolitik einer „völkischen Dichtung“ stellt sich die Frage, welchem Genre die Erlebnisberichte von Lisa Tasche und Gustav Faber zuzuordnen sind. Um diese Frage beantworten zu können, wird, unter Berücksichtigung der oben zitierten Fragestellungen und Thesen, eine vergleichende Inhaltsanalyse der Erlebnisberichte vorgenommen.

\section{2 „Hurra wir zwingen das Glück“: Lisa Tasches Erlebnisse im „weiblichen Arbeitsdienst“}

Lisa Tasches Erlebnisroman „Hurra wir zwingen das Glück. Erlebnisse - Gestalten - Bilder aus dem weiblichen Arbeitsdienst“ schildert ihre autobiografischen Erfahrungen im „NS-Arbeitsdienst“ während eines Jahres, zwischen Herbst 1933 und 1934 (Abb. 8). ${ }^{18}$ Die Autorin entschied sich für den Erlebnisroman, der ,persönliches Erleben verarbeitet und objektiviert“, ${ }^{19}$ als literarische Textgattung. In der „Erzählform“ der dritten Person lässt die Autobiografin ihre Erlebnisse einerseits aus der „Figurenrede“ als „direkte“ oder „indirekte Rede“, als „innere[n] Monolog“ oder als „erlebte Rede“ in Form eines „Gedankenberichts“ aus der „Innensicht“ der Hauptfigur schildern. ${ }^{20}$ Andererseits werden die Ereignisse von

15 Vgl. Langenbucher 1933, $10 \mathrm{f}$.

16 Vgl. Adam 2010, 50.

17 Vgl. Adam 2010, 49f. Zur „Blut-und-Boden“-Literatur vgl. Adam 2010, 271- 292.

18 Vgl. Tasche 1935.

19 Vgl. Art. Erlebnisroman 2017.

20 Vgl. Nünning 2013, 188. 
einer „auktorialen Erzählerin“ wiedergegeben. Ihre „Erzählperspektive“ deckt sich mit dem Erfahrungshorizont der Hauptfigur. Die Narration nimmt keine Sprünge in der Erzählzeit, weder Wechsel in der Erzählperspektive noch Rückblenden vor. Die „Erzählsituation“21 ist insgesamt distanziert und überblickt von einer „Außensicht“ die psychologische Entwicklung der Hauptfigur. Auf diese Weise werden, mit Ausnahme vereinzelter Vorausdeutungen, kaum dramaturgische Spannungsbögen aufgebaut. Die auktoriale Erzählerin beschreibt, kommentiert und reflektiert lediglich die Ereignisse, Gefühle und wirkungsästhetischen Wahrnehmungen der Hauptfigur und einzelner Nebenfiguren. Auf diese Weise führt sie die Leserschaft durch die relativ vorhersehbare „Handlung““.22

Im Klappentext bewirbt der Verlag den Erlebnisroman schwärmerisch mit den Worten:

„Lisa Tasche, die junge Verfasserin dieses Buches, berichtet über den weiblichen Arbeitsdienst. Mit packender Ursprünglichkeit und psychologischer Feinheit bringt sie gerade dem vorurteilsvollen Leser die erzieherische Notwendigkeit des deutschen nationalsozialistischen Frauen-Arbeitsdienstes nahe. Die Verfasserin sagt: Nicht die Vollendung, sondern der Anfang zu der Vollendung braucht die Begeisterung. Diese Begeisterung wird jeder empfinden, der das Buch gelesen hat, das Buch ,Nationalsozialistischer Tat‘.“23

Aus diesem Klappentext lässt sich die vom Verlag erhoffte emotionspolitische Wirkungsmacht erschließen. Der Verlag betont, dass die junge Autorin ein psychopolitisches Feingefühl besäße, mit dem sie der Leserschaft ihre Erlebnisse authentisch vermitteln könne. Darüber hinaus erfülle die Autorin den unterschwellig an sie gerichteten Auftrag, selbst Skeptiker*innen, die es noch zu überzeugen galt, die ,erzieherische Notwendigkeit des deutschen nationalsozialistischen Frauen-Arbeitsdienstes“ vor Augen zu führen. ${ }^{24}$ Der Verlag stellt den Erlebnisroman in eine unmittelbare Beziehung zur „rassenhygienischen“ Erziehungsideologie des NS-Regimes. Die Autobiografin wird vom Verlag, in Referenz an die totalitäre NS-Einheitsstaatideologie, in einer Doppelrolle aus opferbereiter Dienerin und erzieherischer Führerin ihrer Mitmenschen instrumentalisiert. Gleichzeitig ist Lisa Tasche die Autorin des ideologischen Erlebnisromans. Als freiwillige Arbeitskraft im „NS-Arbeitsdienst“ beteiligt sich die junge Frau eigenhändig am Aufbau des NS-Regimes.

Als Autobiografin nimmt sie eine autonome Funktion in der propagandistischen Verbreitung der NS-Arbeitsideologie wahr. Zudem bietet sich die Privat-

21 Vgl. Wolf 2013, 186.

22 Zur Erzähltheorie vgl. Nünning 2013.

23 Tasche 1935, Klappentext.

24 Vgl. ebd. 


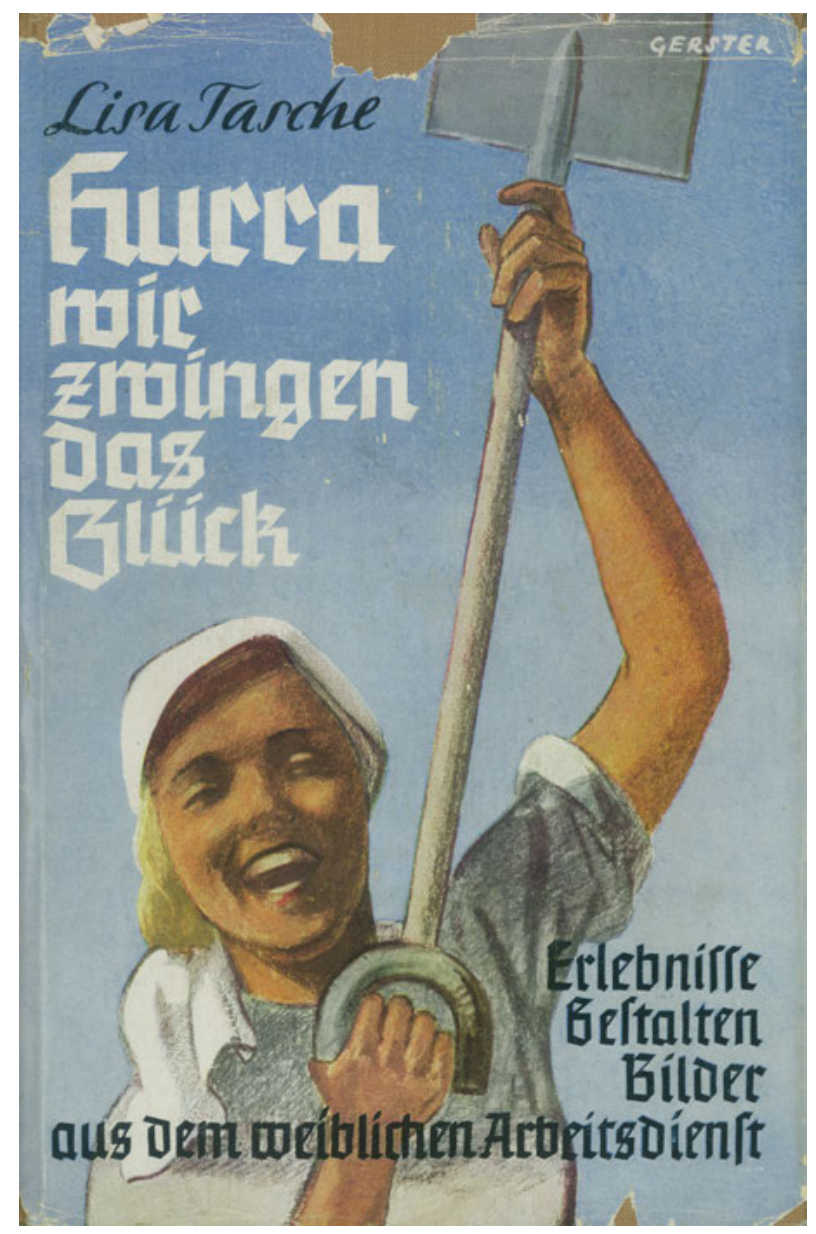

Abb. 8: Lisa Tasche, „Hurra wir zwingen das Glück. Erlebnisse - Gestalten - Bilder aus dem weiblichen Arbeitsdienst“, 1935

person Lisa Tasche mit der Veröffentlichung ihres fotografischen Profilbilds als „rassenstereotypisierte“ Werbeträgerin für den Einsatz im „weiblichen Arbeitsdienst“ an (Abb. 9). Darüber hinaus dient die Illustration der Autobiografin zur Authentifizierung der Autorenschaft des Erlebnisberichts gegenüber der Leserschaft.

An Lisa Tasche zeigt sich exemplarisch, welche Bedeutung und Funktion junge Frauen in ihrer Doppelrolle als staatsideologische Dienerinnen und Führerinnen in der nationalsozialistischen Aufbauphase freiwillig ergriffen hatten. Dieser Befund steht entgegen der längst überholten Forschungsmeinung, Frauen 


\title{
$\mathfrak{E} \mathfrak{i} \mathfrak{j} \mathfrak{a} \mathfrak{C} \mathfrak{a} \mathfrak{d} \mathfrak{e}$
}

?

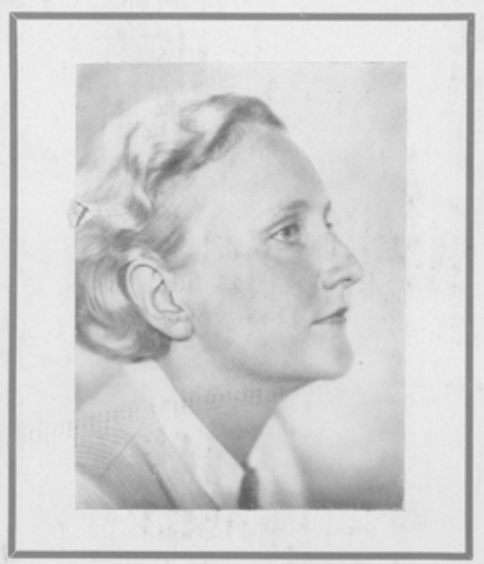

*.

\section{SHurta wir zwingen das Glück}

\author{
Erlebnifje - Geftalten - Bilder \\ aus dem weiblichen 2 rbeitsdienjt \\ mit 3 eidnungen von beinz $\mathfrak{B}$ erfter
}

Abb. 9: Lisa Tasche, „Hurra wir zwingen das Glück. Erlebnisse - Gestalten - Bilder aus dem weiblichen Arbeitsdienst“", [Buchrückseite], 1935

hätten im NS-Regime aufgrund der patriarchal-hierarchisch strukturierten Gesellschaftsordnung als „,rassenhygienische“ Mütter eine lediglich marginale Bedeutung besessen. ${ }^{25}$ Lisa Tasche war folglich kein Opfer des NS-Regimes, sondern

25 Vgl. Frauen. In: Wildt 2008, 98-101, 98f. Zum Forschungsstand ,Frauen im Nationalsozialismus‘ vgl. u. a. Frevert 1989, Owings 1993, Nienhaus 1995, Kundrus 1995, Heinsohn 1997, Manns 1997, Fontaine 2003, Kompisch 2008, Kompisch 2008, Krauss 2008, Frietsch und Herkommer 2009, Kramer 2011, Kramer 2014. 
eine aus ihrer individuellen, leistungsorientierten, selbstdisziplinarischen und autosuggestiven Motivation heraus handelnde Akteurin. In der selbstgewählten ,Rolle“ einer jungen „Volksgenossin“ entsprach Tasche dem geschlechterstereotypisierten NS-Frauentypus. Bereits im Herbst 1933 richtete sie bereitwillig ihre Lebensführung nach der Arbeitsmoral „Kraft durch Freude“ aus. Die „Volksgenossin“ suchte und fand ihre Aufgabe im ,neuen" Gesellschaftssystem (wie so viele junge Arbeitslose jener Zeit) in der Errichtung und Stabilisierung des NSRegimes im „NS-Arbeitsdienst“ als vorläufige Alternative zur beruflichen Vollbeschäftigung.

Tasches ideologische Doppelrolle als exklusiv-individuelle und integrativ-kollektivistische Fürsprecherin eines nationalsozialistischen Glückswissens zeigt im Vergleich zur arbeitspsychologischen Forschung und zu den Anleitungen zur „rassenhygienischen“ und leistungsorientierten Lebensführung in der NS-Ratgeberliteratur eine ambivalente Kontinuität einer affirmativen Gefühlspolitik für junge Arbeitslose und Stellensuchende. ${ }^{26}$

Tasches autobiografische Romanfigur heißt Christine Wendel. Sie entspricht der NS-idealtypischen Erscheinung einer „Arierin“: „Christine ist ein großes, blondes, kräftiges Mädel mit zwei blauen blanken Augen, die wie Kieselsteine

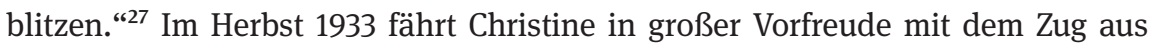
ihrer Heimat in Lindau am Bodensee in das ihr unbekannte „Potsdam bei Berlin“. ${ }^{28}$ Dort soll die 23-jährige Frau für 13 Wochen ihren Dienst verrichten. Vom nationalsozialistischen Gemeinschaftserlebnis ergriffen, beantragt Christine eine Verlängerung und bleibt insgesamt ein Jahr im „NS-Arbeitsdienst“. ${ }^{29}$

Welche emotionspolitischen Strategien und Mechanismen scheinen Christine von der NS-Arbeitsmoral „Kraft durch Freude“ überzeugen zu können? Die junge Frau ist fasziniert vom emotionspolitischen „Band“, das sich ideologisch immer enger um die einzelnen „Kameradinnen“ lege, je länger sie in dieser von der Außenwelt abgeschirmten, totalitären „Gemeinschaft“ lebten: „[...] ein Band, das durch das ganze Volk laufen wird, um die Idee des Nationalsozialismus weiterzutragen. “30 Insbesondere im „Arbeitsdienstlager“ auf dem Land nähmen sich die

26 Auch bei Faber ist zu lesen: „,Arbeitslos. -““ sprach der gelernte Tischler und Arbeitskamerad im Erlebnisroman von Faber, „,Das waren wir schließlich ja alle, bevor wir hier wieder Arbeit fanden [...]““. Vgl. Faber 1934, 52.

27 Vgl. Tasche 1935, 7.

28 Zur authentischen Beglaubigung des autobiografischen Berichts druckte der Verlag unter Namensänderung auf „Christine Wendel“ den offiziellen „Zulassungs-Bescheid“ ab. Vgl. Tasche 1935, 184.

29 Vgl. ebd., 184.

30 Ebd., 184. 
„Kameradinnen“ nicht nur rascher als eine „Gemeinschaft“ wahr, sondern erlebten und fühlten diese intensiver als in der ablenkungsreichen Stadtnähe zu Potsdam. ${ }^{31}$ Tasches sozialromantizistische Utopie einer matriarchalen Gesellschaftsordnung im Nationalsozialismus zeugt von der ambivalent (anti-)modernistischen Einstellung der Autorin gegenüber dem scheinbar ursprünglichen und moralisch ,unverdorbenen ' Landleben unter künstlich erzeugten vormodernen Bedingungen. ${ }^{32}$

Wenn man Christines Bericht Glauben schenken möchte, erlebte die 23-jährige Frau während des „weiblichen Arbeitsdiensts“ die beste Zeit ihres Lebens. Das „literarische Motiv“33 des Erlebnisromans ist die emotionspolitische Arbeitsmoral der NS-Propaganda „Kraft durch Freude“: Die wie beiläufig platzierten Beschreibungen, Kommentare und Reflexionen der auktorialen Erzählerin sollen bei den Leser`innen den Eindruck erwecken, dass der „Arbeitsdienst“ als eine harmonische, da „rassenhygienisch“ homogene, „glückliche“ Arbeitsgemeinschaft realisiert werden konnte (wie es sich Ehrenbert, Briefs und Giese in ihren sozialromantizistischen, rassistischen Vorstellungen über eine vormoderne „Werkgemeinschaft“34 wohl erträumt hätten).

Sei es auf Äckern oder Feldern, in Handwerksstuben oder auf Bauernhöfen; die Erzählerin wird nicht müde, die jungen Frauen zu beschreiben, wie sie - von der überhöhten NS-Arbeitsmoral beflügelt - ihre Arbeit als singendes Kollektiv verrichten:

„Wenn Christine dieses gesunde Land, die Begeisterung dieser jungen Gemeinschaft sieht, die sich im Singen immer wieder zusammenschließt, bis sich eine einfache Kameradschaft gebildet hat, stellt sie fest, daß jeder den Arbeitsdienst selbst erleben muß, um ihn zu verstehen. Wird die Zeit des Arbeitsdiensts für die Mädel vorüber sein, kommen sie als gesunde Menschen in die Stadt zurück, treten damit aus voller Überzeugung in den unkündbaren Vertrag des nationalsozialistischen Staates.“35

Die autobiografische Erzählung über Christine Weigels Werdegang im „weiblichen Arbeitsdienst“" liest sich wie eine Analogie zu den Anleitungen im Ratgeber „Der Weg ins Glück. Durch Selbstbemeisterung zur Lebensmeisterung“ von Will Rinne. ${ }^{36}$ Selbst eintönigste Arbeiten werde angeblich „glücklich“ singend verrichtet.

31 Vgl. ebd., 183.

32 Zur Rezeption der deutschen Romantik im Nationalsozialismus vgl. Klausnitzer 1999.

33 Vgl. Lubkoll 2013, 542.

34 Zum Begriff vgl. u.a. Albrecht 1929. S. auch Kap. 12.

35 Tasche 1935, 172.

36 Vgl. Rinne 1941. 
Um ihre erlebte Begeisterung in Worte $\mathrm{zu}$ fassen, verwendet die Erzählerin emotives (Gefühlswörter) wie „lachende, junge, frohe Gesichter“37 oder die Metapher der niemals untergehenden, strahlenden „Sonne“ in Referenz zum Hakenkreuz, dem indogermanischen Sonnen- und Glückssymbol. ${ }^{38}$ Die Gefühlswelt der „Kameradin“ Lucie wird exemplarisch wie folgt beschrieben:

„Lucie hat ein Gedicht gemacht. Oh welch Freude! Sie glüht innerlich, ist lauterer [sic] Stolz. [sic] - aber noch ein anderes Ereignis hat Lucie so seltsam froh gemacht. Sie ist vor vierzehn Tagen zur Gruppenführerin befördert worden. [...] Durch ihre Beförderung durch ihren schon lang gefaßten Plan ein Gedicht zu machen - dann das Gelingen des Gedichtes, eben durch all dies ist in Lucie etwas Sonniges wach geworden, das ihrem früheren Leben fremd war. Das Leben - das Leben - denkt Lucie. [...] Ja, dieses Leben! Mehr kann sie heute nicht sagen. Es genügt auch. Lucie braucht keine Worte. Läßt die Freude tief, tief in sich sinken, hält sie im Verborgenen fest, Wochen hindurch. Dann strömt sie ihr Glück erregt atmend wieder aus. Wochen hindurch. [sic] Als Überraschung hat sie es [das Gedicht] noch schnell mit der Melodie eines Marsches ausgestattet. Jetzt singen vier Mädel am Fenster, singen, singen... [sic] Rauschender Beifall, ohne Ende. ,So', sagt sie, hat das strahlende Gesicht von der Welt. In diesem so liegt Lucies Zukunft im Lager beschlossen. Noch etwas hat Lucie erlebt. [...] Man sieht einen jungen hübschen Burschen jeden Mittwoch um acht Uhr unter einer Laterne gegenüber dem Lager stehen. [Ein paar Monate später] ,Bin längst verheiratet, mit - na, weißt ja.' Sie lacht glücklich.“39

Auf mehreren Ebenen entfaltet sich in dieser Erzählung die wirkungsmächtige Illusion einer affirmativen Gefühlspolitik: Auf der Ebene einer individuellen Selbstverwirklichung als „volkshafte“ Dichterin, leistungsorientierte „Gruppenführerin“ sowie „rassenhygienische“ Freundin und Ehefrau gelingt Lucie, nach dem nationalsozialistischen Selbstoptimierungsprinzip, ein sozialer Aufstieg (um den Christine sie sehr beneidet). Auf der Ebene einer gemeinschaftsfördernden Zusammengehörigkeitserfahrung leitet Lucie in der individuell-leistungsorientierten und zugleich gemeinschaftsstiftenden-paramilitärischen Doppelrolle als Liedermacherin und „Gruppenführerin“ ihre „Kameradinnen“ zur Gesangsaufführung an und erntet dafür Beifall und einen noch größeren Reputationsgewinn.

Das Prinzip der „rassistischen Leistungsgesellschaft“"40, als ein Erfahrungsraum von praktiziertem „Glück“, wird im „NS-Arbeitslager“ wiederholt beschrieben. Individuelles „Glück“ wird als praktizierbares „Glück“ in der Gemeinschaft in einer emotionspolitischen Wechselwirkung zum leistungsorientierten Dienst erwirkt: Einerseits auf einer kollektiv erfahrbaren Ebene, andererseits auf einer in-

37 Tasche 1935, 27.

38 Vgl. ebd., 276. „Sonnen“-Metapher bei Faber, vgl. Faber 1934, 91, 286.

39 Tasche 1935, 66-69.

40 Vgl. Süß 2018, 110. 
dividuellen Ebene durch den sozialen Aufstieg als selbstdisziplinarisches „Glück“ der „Selbstbemeisterung“.

Tasches Erlebnisroman kann aus einer literaturhistorischen Perspektive in die Wissenskontinuität eines Erziehungsromans gestellt werden. ${ }^{41}$ Der Erziehungsroman (als Bildungsroman der Aufklärung) war in der Regel eine literarische Darstellung psychologischer Prozesse einer Hauptfigur, die im Widerstreit mit sich und ihrer Umwelt steht. ${ }^{42}$ Den Litertaturtheorien der Aufklärung zufolge wurde anhand der Hauptfigur versucht, neben einer ,einsehbaren Ordnung der Natur, die Forderung nach einer allzeit kritischen Selbständigkeit der Vernunft [...], die Möglichkeit einer progressiven Vervollkommnung des Einzelnen wie der Gesellschaft" abzubilden. ${ }^{43}$ Die Forderung der Aufklärung nach Kritikfähigkeit und einer „Selbständigkeit der Vernunft“ wird bei Tasche letztlich nicht eingelöst. Ihr Entwurf einer „rassenmoralischen“ Lebensführung entspringt keinem humanistischen Menschenbild und keiner bürgerlichen Emanzipationsbestrebung nach einem moralisch ,guten' Handeln im Sinne Kants. Doch die literaturtheoretischen Ansprüche der deutschen Aufklärung, die Leser^innen durch den literarischen „Empfindungsreichtum“44 emotional zu ergreifen und dadurch den Menschen zu einer allumfassenden Bildung und „progressiven Vervollkommnung des Einzelnen wie der Gesellschaft “ ${ }^{45} \mathrm{zu}$ führen, war der NS-Literaturpolitik nicht fremd. ${ }^{46}$ Die Literaturtheorien der deutschen Aufklärung verfolgten in ihrem wissenshistorischen Denkstil einer „literarischen Anthropologie“477 ein übergeordnetes Ziel:

„Wie das aufgeklärte Lebensideal im Ganzen, so steht auch die Wahrnehmung der Funktion von Literatur ganz im Zeichen der ,Vervollkommnung، des Menschen und des Erreichens größtmöglicher Glückseligkeit.“48

41 Als ein prominentes Beispiel für einen Erziehungsroman gilt Jean-Jacques Rousseaus „Emil oder Über die Erziehung“ („Emil, ou, De l'éducation“) von 1762.

42 Zur Literatur der Aufklärung vgl. Matuschek 2015.

43 Vgl. Jacob 2013, 39.

44 Ebd., 40.

45 Vgl. ebd., 39.

46 Vgl. ebd., 41. Schiller nannte es die „ästhetische Erziehung des Menschen“ (1759). Zur NSTheaterpolitik s. Kap. 15. Zu den Erziehungskonzepten der deutschen Aufklärung vgl. Kenklies 2015. Zur Rezeption „deutscher Klassiker“ im Nationalsozialismus vgl. u. a. Albert 1994a.

47 Der wissenshistorische Ansatz einer „literarischen Anthropologie“ zeichnete sich bereits in Johann Gottfried von Herders (1744 - 1803) Fragment „Über die neuere deutsche Literatur“ (1766 1767) ab und wurde später in Sulzers „Allgemeine Theorie der schönen Künste“ (1771-1774), insbesondere in den Passagen zu „Ausdruck“, „Empfindung“ und „Nachahmung“ weiter ausgeführt. Vgl. Herder 1767. Vgl. Sulzer 1994. Vgl. Jacob 2013, 40.

48 Jacob 2013, 40. 
Wie unterschied sich Tasches literarische Glücksdarstellung von jener in den Literaturtheorien der Aufklärung? Der von Tasche beschriebene „Weg ins Glück“49 ist ein ideologischer Weg, der ein angeblich gefühlshistorisch und anthropologisch konstruiertes „eugenisches“ „Rassegefühl“ einer vernunftorientierten Ideologiekritik voranstellt. Mit den moralischen Lehrsätzen der philosophischen Aufklärung, wie sie Gotthold Ephraim Lessing (1728-1781) in seiner Trauerspieltheorie zur Diskussion stellte, übernehme die Literatur der Aufklärung den diskursiven Wissenstransfer zwischen ,theoretischer Einsicht und praktischem Handeln“, so der Literaturwissenschaftler Jacob. ${ }^{50}$ Der nationalsozialistische Erlebnisroman Tasches ist ein Beispiel, wie diese literarische Prämisse einer aufklärerischen Wissenspraktik im machtpolitischen Kontext der nationalsozialistischen Literaturpolitik umgedeutet wurde. Die Ziele der Erziehungspraktik der Aufklärung mit einer ,,natürlichen‘ Sprache [...] ,sinnliche Vorstellungen“ der Literatur“ zu kreieren, die „eine ,anschauliche“ bzw. lebendige“ Erkenntnis des Allgemeinen im Besonderen [...]“ erbrächten und „den praktischen Willen in besonderer Weise zur Tugend“ anreizten, wurden übernommen und ideologisch verfremdet. ${ }^{51}$ Beschreibungen einer „Empfindsamkeit“, wie sie die Literaturwissenschaft historisch für die europäische Aufklärung in den Jahren von 1740 bis 1790 verortet, ${ }^{52}$ findet man in Tasches nationalsozialistischem Erlebnisroman in ambivalenter Form wieder, wie das folgende Beispiel zeigt:

„Christine beobachtet unablässig das Handeln und Denken ihrer Kameradinnen, mit einer Überlegenheit, die sich, unangenehm bemerkt auf die Mädel überträgt. Sie bekommen Hemmungen, sobald Christine erscheint, selbst wenn sie manchmal ausgelassen wie ein Kind ist. Christine staunt über die natürlich-geistige Formung im Arbeitsdienst, grübelt über alles nach, sieht die Entwicklung einer Gemeinschaft ganz allmählich vorwärts gehen, vergißt aber durch das Beobachten und Nachdenken, selbst Schritt zu halten. Fühlt sich oft vergessen - allein. ${ }^{\text {"53 }}$

Die literarische Darstellung von Christines Empfindungen ${ }^{54}$ weist aufgrund ihrer charakterologisch, natürlichen' Autorität auf ihre Karriere als weiblicher Führungstypus im NS-Regime hin. Wie die dramaturgische Erzählstruktur Christines

49 Vgl. Rinne 1941.

50 Vgl. Jacob 2013, 41. Mehr zu Lessing s. Kap. 15.

51 Vgl. Jacob 2013, 41.

52 Zur Rezeption „deutscher Klassiker“ im Nationalsozialismus vgl. u.a. Albert 1994a. S. auch Kap. 15 zur NS-Theaterpolitik.

53 Tasche 1935, 45.

54 Zur „Empfindsamkeit“ in der Aufklärung vgl. Sauder 2015. 
Weg ins „Glück“ konstruiert, lässt sich an der psychologischen Entwicklung der autobiografischen Romanfigur aufzeigen.

$\mathrm{Zu}$ Beginn des Romans gehört Christine selber noch zu den Ideologieskeptiker*innen. Bald nach der Ankunft wird sie in eine „große, komische Kittelschütz“ gesteckt und man bindet „,ihr kurz und bündig ein Kopftuch um“. ${ }^{55}$ Nach dieser visuellen Transformation zwecks Entindividualisierung zeigt ihr Grete, die „Führerin“, das „Arbeitsdienstlager“. Wochenlang fühlt Christine „nur in manchen Augenblicken instinktiv, daß sie dieser Idee mit ihrer ganzen Begeisterung verfällt. Auch weiß sie noch nicht, ob sie alles bejahen oder verneinen soll."56 Christines Aufgabe im Lager besteht zunächst darin, unter strenger Aufsicht und Kontrolle stundenlange Streicharbeiten an Wirtshausstühlen zu verrichten. Nach einer Weile kommen Christine Zweifel. Sie hatte sich die „Arbeitsdienst“-Zeit anders erträumt: „[D]ie Eintönigkeit, Mauern, die leeren, unwohnlichen Räume“ wirken auf die junge Frau „dumpf“ und „schwer.“57 Sowohl ihre „Tatkraft“ als auch ihr „Wille“ sind auf dem Tiefpunkt angelangt.

An dieser Stelle im Roman erhalten die Leser`innen ihre erste Lektion in der autosuggestiven und leistungsorientierten Selbsterziehungspraktik: Christine wisse zu diesem Zeitpunkt noch nicht, was „Kameradschaft“ und „Gemeinschaft“ sei, „daß zur Verwirklichung brennender Wünsche äußerster Wille gehört, der Wille zur Tat“.$^{58}$ Folglich lautet die Losung der auktorialen Erzählerin: „Traum ist Wunsch zum Ziel - Wunsch läßt Wille und Tat entstehen. “59 Christine durchläuft in wissenshistorischer Kontinuität zur arbeitspsychologischen Ratgeberpraktik einen kontinuierlichen Umerziehungsprozess, der im Rahmen der NS-Gefühlspropaganda auf die Leser^innen (selbst-)erzieherisch einwirken sollte.

Die Erzählerin lässt die Leser^innen an Christines emotionspolitischem Erkenntnisprozess als innerem Monolog unmittelbar teilhaben. Christine hadert mit sich, mit ihren Vorurteilen gegenüber den anderen, hat „Heimweh“60 , fühlt sich einsam und zugleich ausgestellt in Anwesenheit dieser „fremden Menschen“. ${ }^{61} \mathrm{Ihr}$ kommt ein erlösender Gedanke: „Gemeinschaftsmensch“ zu sein bedeute „Disziplin“ und die „Bereitschaft“, dazugehören zu wollen. „Enttäuschungen sind da. Jeder erlebt sie, muß sie erleben, um die Tiefen einer Gemeinschaft zu fühlen“, so schlussfolgert Christine im Sinne der leistungsorientierten NS-Selbsterziehungs-

55 Vgl. Tasche 1935, 19.

56 Vgl. ebd., 41.

57 Vgl. ebd., 22.

58 Vgl. ebd., 22.

59 Vgl. ebd.

60 Vgl. ebd., 27.

61 Vgl. ebd., 24. 
praktik. ${ }^{62}$ Tasches psychopolitische Erkenntnis über ein sich im geteilten Erfahrungsschatz herausbildendes Gemeinschaftsgefühl erinnert an Mannheims wissenssoziologische Theorie über „Ideologie und Utopie“ (1929). Wie bereits gezeigt, erachtete der Wissenssoziologe gemeinschaftsstiftende Erfahrungen als ein wesentliches Element für die Ideologiebildung einer Gesellschaftsutopie. ${ }^{63}$

Nach paramilitärischen Drillsporteinheiten und Marschübungen hört Christine ihren ersten NS-ideologischen Vortrag eines „Doktor Burg“ zum Thema „Was ist Glaube?“. Die Propagandaantwort lautet: „Rassenbewußtsein ist Empfindung - wer sie nicht hat, dem muß sie geweckt werden, denn jeder arische Mensch trägt Rassegefühl in sich, wenn auch oft nur als ungeschürten Funken““ ${ }^{64}$ Antiklerikal und geschlechterstereotypisiert versucht Burg, die Hörer*innen davon zu überzeugen, dass „Rasse“ weder eine Ideologie noch eine Frage des Glaubens sei, wie es Religionen fälschlicherweise lehrten. „Rasse“ sei eine „Empfindung“, die in jeder „Volksgenossin“ geweckt werden könne. ${ }^{65}$ Dieser antiklerikale Erweckungsgedanke einer „rassenhygienischen“ Gefühlspolitik entfaltet in den nächsten Tagen in Christine eine emotionspolitische Wirkungsmacht. Ein erstes ideologisch auslösendes Gefühlsmoment wird Christines Beobachtung des kollektiven Gesangs der „Kameradinnen“, die am Morgen „froh an die Arbeit marschieren“. ${ }^{66}$

\subsection{Gemeinschaftsgesang als arbeitspsychologische Körperpraktik einer kollektiven Glückserfahrung}

Das musikästhetisch wahrnehmbare Glückserlebnis dringt tief in Christines Psyche ein und weckt in ihr die Sehnsucht nach Zugehörigkeit:

„Dieses Singen ist unbeschreiblich, aufleuchtend hell, es ruft, drängt zu der Verbundenheit einer Gemeinschaft. Nimmt ihr [Christine] plötzlich alle Fremdheit.“67

Der Gemeinschaftsgesang wird bei Tasche als zentrales musikästhetisches Instrument eingesetzt, um eine wirkungsmächtige Illusion eines psychopolitischen Erfahrungsraums zu schaffen, wie folgendes Beispiel zeigt.

62 Vgl. ebd., 24

63 Vgl. Mannheim 2015.

64 Vgl. Tasche 1935, 32.

65 Vgl. ebd., $32 \mathrm{f}$.

66 Vgl. ebd., 40.

67 Ebd., 40. 
Zur offiziellen Einweihungsfeier des „Arbeitsdienstlagers“ wird ein Saal „mit Hakenkreuzfahnen festlich geschmückt““ ${ }^{68}$ Eine Rednerin propagiert die Ziele und „Ideen des deutschen Frauenarbeitsdiensts“ und appelliert an die „Pflicht als Frau [...] Liebe, Wärme, Güte und Verständnis zu schaffen“. ${ }^{69}$ Die Parole des „Arbeitsdienstes: ,Arbeit für dein Volk adelt dich selbst““ leitet zu einem Lied des „weiblichen Arbeitsdiensts“ über:

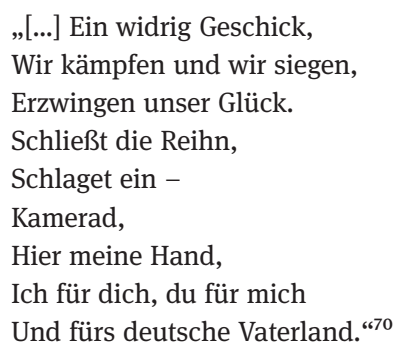

Das musikpädagogische Wissen um ein kollektives Glücksempfinden beim gemeinsam praktizierten Singen wird von der emotionspolitischen NS-Erziehungspolitik instrumentalisiert. Wolfgang Stumme, Herausgeber der „Schriften zur Musikerziehung“, erläutert in seinem „Ratgeber“ mit dem Titel „Was der Führer der Einheit vom Singen wissen muß“ (1940) $)^{71}$, wie sich die kollektive Körperpraktik ideologisch nutzbar machen ließe. Das Ziel der kollektiven Gesangspraktik formulierte Hitler im Vorwort von „Unser Liederbuch“ (1939), auf das sich Stumme bezieht:

„[D]ie Lieder unseres Volkes [...] werden mit Inbrunst gesungen, denn in ihnen lebt die Hoffnung und die Sehnsucht aller Deutschen. Denn welch schönere Hymne für ein Volk kann es geben als jene, die ein Bekenntnis ist, sein Heil und sein Glück in seinem Volke zu suchen und sein Volk über alles zu stellen, was es auf dieser Erde gibt." ${ }^{\text {72 }}$

In totalitärer Analogie zur „volkskundlichen Dichtung“73 bei Langenbucher beschwört Stumme den nationalsozialistischen Kulturwert des „deutschen“ Volkslieds. Die jungen Menschen sollten von den als oberflächlich empfundenen „Schlagern“ weg und hin zu „ernsthaften“ Volksliedern geführt werden. Die

\footnotetext{
68 Vgl. ebd., 102.

69 Vgl. ebd., 102.

70 Ebd., 103.

71 Stumme 1940, 6.

72 Adolf Hitler, Vorwort aus „Unser Liederbuch“, zit. nach Stumme 1940, 21.

73 Vgl. Langenbucher 1933.
} 
Volkslieder hätten einen Jahrhunderte überdauernden Kulturwert. Das Singen dieser Lieder könne folglich eine emotionale Bindung zu diesem Kulturgut erwecken. Emotionspolitisch argumentiert, gewännen die Singenden dadurch „Lebenskraft“ und, wie Hitler meinte, „Heil“ und „Glück“.

Stumme entwarf zahlreiche Richtlinien, nach denen sich die „Formationsführerinnen“ als „Erzieherinnen“ der NS-Musikpädagogik zu verhalten hätten. Die charakterologische Persönlichkeit des „Formationsführers“ war dabei entscheidend für den emotionspolitischen Erfolg der Gesangspraktik. An „Heimabenden“, auf dem „Marsch“, auf „Fahrt[en]“ und im „Lager“ sei für die „Führerpersönlichkeit“74 ausschlaggebend, dass sie eine „größt mögliche Lebendigkeit“ ausstrahle. Auf diese Weise könne es der „Führerin“ massenpsychologisch gelingen, eine emotionale Bindung zu sich zu entwickeln und dadurch eine Mehrheit unter den Sänger`innen für sich zu gewinnen. Darüber hinaus könne die „Führerin“ über dieses kollektive Verbundenheitsgefühl hinaus auch ein Gefühl der „Gemeinschaft“ unter den Sänger^innen erwecken. Die emotionspolitische Begründung des NS-Musikpädagogen lautete paramilitärisch:

„Singen ist der schönste Ausdruck unserer Lebensfreude, hier im Gleichklang der Schritte einer Lebensfreude einer marschierenden Kameradschaft. Beim Singen gibt es keine verzerrten, sondern nur frohe und heitere Gesichter [...]. Unser Singen steckt voll Freudigkeit, ist aber zuchtvoll, straff und gesund dabei. Beim Singen herrscht deshalb Disziplin wie bei den Ordnungsübungen.“75

Stumme ist von der emotionspolitischen Wirkungsmacht des „Gemeinschaftssingen[s]“ überzeugt. Deshalb fordert er von den „Führerinnen“ einen möglichst passenden Liedtext anzustimmen: Verrichte der „Trupp“76 kräftezehrende Arbeiten, so solle man ein Lied wählen, worin die „Kraft durch Freude“ am Arbeiten besungen würde, um deren wirkungsmächtige Illusion in der „Gemeinschaft“ $z u$ erzeugen. Darüber hinaus sollten die Lieder auswendig vorgetragen werden, sodass im Sinne der NS-Gefühlspolitik nicht „mit dem Kopf“, sondern mit dem „Herzen“ gesungen würde. ${ }^{77}$ „Das Begreifen und Erfassen des Liedinhalts bis in seine Tiefen hinein und der geschlossen-mannschaftliche und stimmlich-gesungene Klang der singenden Formation“ seien das Ziel. ${ }^{78}$ Der Inhalt des Liedtextes, die gesungenen Worte sollten im musikalischen Verbund aus Rhythmus und

74 Stumme 1940, 6.

75 Ebd., 8f.

76 Faber 1934, 51.

77 Vgl. Stumme 1940, 7.

78 Vgl. ebd., 8. 
Melodie ein synästhetisches „Gemeinschaftserlebnis“ eines kollektiven „Glücks“ erwecken und erziehungsideologisch verinnerlicht werden. ${ }^{79}$

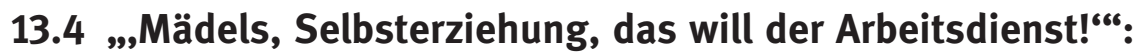 „Gemeinschaftserfahrung“ eines erzwungenen „Glücks“}

Beim „weiblichen Arbeitsdienst“ handelte es sich, neben der Verrichtung von Haus- und Hofarbeiten, in erster Linie um ein emotionspolitisches Erziehungslager. Einer kritischen Leserschaft wird dies bereits nach den ersten Seiten von Tasches Erlebnisroman bewusst. In der Realität entsprach dieses Erziehungskonzept sowohl der musikpädagogischen NS-Gefühlspolitik eines Wolfgang Stumme als auch der „rassenhygienischen“ Erziehungsideologie der Inspekteurin der „BDM-Führerinnenschulen“ Hella Schümann. Sie betont in ihrem Aufsatz „Unsere Schulen. Stätten der Besinnung und der Kraft“ die emotionspolitische Bedeutung der NS-Organisationen und sieht, ergänzend zur nationalsozialistischen „Wissensvermittlung“80 in den Schulen, den „Bund deutscher Mädel“ als psychopolitischen Erlebnisort an. Hier sollte die Ideologie der „Volksgemeinschaft" praktiziert und dadurch erleb- und erfahrbar gemacht werden:

„Während die Schule, die der Staat geschaffen hat, Wissensvermittlung ist, soll bei uns das Hauptgewicht liegen auf dem Erleben der Volksgemeinschaft und dem Wissen um unser Ziel: der klaren Haltung auf allen Lebensgebieten. Es ist einerlei, in welchem Teile Deutschlands unsere Schulen liegen, ob in Nord, Süd, Ost oder West, sie alle sind aus dem gleichen Geist heraus geschaffen worden, aus dem Willen zur Formung und Führung der heranwachsenden Mädchengeneration. [...] Der Wille zur Lebensbejahung, zum Einsatz für Volk und Reich, zum ständigen Bereitsein soll so tief hineingetragen werden in unsere Mädel, daß er ihnen ureigenes Gut wird. “81

„Reichsfrauenführerin“ Gertrud Scholtz-Klink (1902-1999), die 1934 „Reichsleiterin“ des „Deutschen Frauenarbeitsdiensts“ wurde, besuchte die jungen Frauen in Tasches Erlebnisroman persönlich. Diese „Erzieherinnen“ vermittelten den jungen Frauen an den sogenannten „Heimabenden“ die geschlechterstereotypisierte Bedeutung und „rassenhygienische“ Aufgabe der „deutschen Frau“ in der NS-Geburtenpolitik und dem von ihr geforderten „Willen zur Lebensbejahung

79 Vgl. ebd., 8.

80 Schümann 1935, 22.

81 Ebd. 
zum Einsatz für Volk und Reich“, wie es bei Schümann in post-nietzscheanischer Rezeption heißt. ${ }^{82}$

Das folgende Beispiel zeigt, wie die NS-Erziehungspropaganda im Wesentlichen an das arbeitsideologische Glückswissen einer leistungsorientierten und emotionspolitischen Selbsterziehungspraktik jeder einzelnen „Volksgenossin“ appellierte: Nachdem Christine neun Wochen im „Arbeitsdienstlager“ verbracht hatte, fällt nicht nur ihr, sondern auch der Lagerleiterin, „Fräulein Eickmann“, eine schleichende Ermangelung der anfänglichen „Begeisterung“ am „Arbeitsdienst“ unter den Dienstleistenden auf. Aus diesem Grund sieht sich Eickmann eines Abends gezwungen, einen eindringlichen Vortrag über die NS-ideologische „Gemeinschaftsfrage“ zu halten. Nicht zuletzt im Wissen um das baldige Ausscheiden einiger Dienstleistenden gibt sie den „Volksgenossinnen“ emotionspolitische Anweisungen, wie sie (vergleichbar mit C.H. Huters Ratgeber) durch eine selbstdisziplinarische „Selbsterkenntnis“83, „Willensschulung zur Persönlichkeitskultur“84 und „richtige Menschenbeurteilungskunst“85 ihr „Glück“, im Sinne der „NS-Rassenmoral“, erzwingen müssten:

„,Meine Aufgabe, mein Bestreben ist es, eine starke Gemeinschaft zu bilden. Ich habe aus vielen kleinen Beobachtungen gesehen, daß ihr euch über die Gemeinschaft noch nicht ganz klar seid. Darum habe ich euch heute Abend zusammengetrommelt. Denn schon in einigen Wochen werden die ersten Mädels den Arbeitsdienst wieder verlassen. Wozu sind wir hier im Arbeitsdienst? Weil wir den Ausgleich zwischen den Intellektuellen, den einfachen Menschen schaffen wollen und werden. Das Eine kann ohne das Andere nicht bestehen. Unter den Millionen sind nur sehr wenige Intellektuelle, um etwas wirklich Produktives im Sinne der Volksgemeinschaft hervorzubringen. Darum wollen wir uns mit dem Intellekt nicht befassen. Ihr dürft natürlich nicht moralische Wertungen durch verstandesmäßige Überlegung zu gewinnen versuchen, sondern erstrebenswert soll für euch die geistige Natürlichkeit bleiben. Das sind die Fragen, die euch unbewußt zersplittert haben. Jeder will im Recht sein [...] vergißt, daß hier im Arbeitsdienst die Gemeinschaftsfrage im Vordergrund steht. [...] Einmal müßt ihr's doch begreifen!

Fräulein Eickmann spricht scharf, energisch, unterstreicht mit der geballten Faust jedes Wort. ,Gemeinschaft - ist erste Forderung des Staates, Pflicht, Zweck der Jugend.` Die Mädchen horchen auf, straffen sich. [...]

,Eure Begeisterung zum Arbeitsdienst kann sich nur halten, wenn ihr bewusst alle Seiten seht - euch nicht durch die Schwäche [...] beeinflussen laßt. [...] Das sind die Grundlagen zur Tatkraft einer freudigen Arbeit.' [...]

Fräulein Eckmann überlegt jedes Wort. Denkt daran, daß auch Sechzehn-, Siebzehnjährige unten den Mädeln sind. [...]

82 Vgl. ebd. 1935, 22.

83 Huter 1940, 4.

84 Ebd., 2, 56.

85 Ebd., 4. 
,Mädels, Selbsterziehung, das will der Arbeitsdienst! Dazu gehört in erster Linie die Klarheit des Selbsterkennens, das vorurteilslose gesunde starke Urteil über sich und andere - vor allen Dingen das Vertrauen. Der Gedanke der Selbsterziehung kann euch nicht früh genug nahegelegt werden, alles beginnt in dem Augenblick, in dem ihr euer erstes tiefes seelisches Erlebnis fühlt, zwischen Wollen, Können hin- und hergerissen werdet. [...] wenn ihr eurer Werte, Schwächen, Stärken bewußt seid. Da beginnt der Kampf um die sittliche Selbstbehauptung - es geht um Sein oder Nichtsein!

Das Gefühl des Opfers, das Opfer der eigenen Selbstaufgabe zum Wohle des Ganzen, die frohe Bereitwilligkeit, das freudige Offensein allen Dingen gegenüber, verbunden mit einem gesunden Selbstgefühl, das sich im natürlichen Lebenskampf offenbart, muß eine Selbstverständlichkeit werden. [...]

Das Wort Jugend verkörpert Freiheit - Mut - Kraft - Schönheit - Freude - Leid [...] Durch das Gefühl erlebt ihr - Erleben ist Leben - das Leben lehrt euch, Vernunft zu brauchen, die harmonische Bindung von echtem Gefühl und wahrer Vernunft muß euch zum Gemeinschaftsmenschen stempeln. [...]

Diese Erkenntnis richtet euren Blick nach Innen - zum Quell eures Seins. Jugend ist Optimismus, ist freudiger Entschluß, das Leben zu gewinnen; ist Blut, Mut, siegreicher Glaube. Nicht die Vollendung - der Anfang zu der Vollendung braucht eure Begeisterung! Gute Nacht! ‘ “86

In diesem propagandistischen Erziehungsvortrag macht Eickmann den jungen Frauen klar, dass der Erfolg der nationalsozialistischen Gesellschaftsutopie in der Eigenverantwortung der jungen Menschen läge. Exemplarisch steht dafür ihre Parole: „Mädels, Selbsterziehung, das will der Arbeitsdienst!“887 Ihre autosuggestive Selbsterziehung sei die Grundlage für den massenpsychologischen Mobilisationsprozess zum Aufbau, zur Stabilisation und zum Erhalt des NS-Regimes. (Aus heutiger Sicht drängt sich die Frage auf: Was wäre geschehen, wenn sich die jungen Erwachsenen dem Dienst dieser affirmativ propagierten Gefühlspolitik einer „rassenhygienischen“ Körperkultur verweigert hätten?)

Wie reagierte Christine auf die „rassenhygienischen“ Vortragsreihen? Ein Anflug emotionaler Überforderung überrollt die 23-Jährige: „Christine weint in ihre Decke hinein. Die Welt ist ihr so groß geworden, daß sie es nicht mehr fassen, daß sie es niemandem sagen kann." ${ }^{88}$ Die totalitäre Anweisung an die Jugend, eine nationalsozialistische Selbsterziehungskultur zur emotionspolitischen Lebensführung zu erheben, wirkt auf Christine überwältigend. Insbesondere die Rhetorik der ihr übertragenen Verantwortung für das Gelingen der Gesellschaftsutopie löst in Christine den von Schümann beschriebenen, emotionspolitischen Schlüsselmoment aus:

86 Tasche 1935, 86-90.

87 Vgl. ebd., 88.

88 Vgl. ebd., 91. 
„[...] alles beginnt in dem Augenblick, in dem ihr euer erstes tiefes seelisches Erlebnis fühlt, zwischen Wollen, Können hin- und hergerissen werdet. Wenn ihr vorwärts drängt, verwirrt stillesteht [sic], euch zum ersten Male selber erlebt, wenn ihr euch eurer Werte, Schwächen, Stärken bewußt seid.“89

Nach diesem einschneidenden emotionspolitischen Erweckungsmoment geht Christine Tag für Tag ein Stück mehr in der „gleichgeschalteten“ ,Rolle“ der entindividualisierten „Volksgenossin“ auf. Immer seltener äußert sie Kritik an der ideologischen Doktrin über das von den jungen Frauen geforderte „Rassenbewusstsein“ oder an der individuell aufzubringenden Selbstdisziplin zur leistungsorientierten Perfektionierung der ,Rolle und Aufgabe einer „deutschen Frau“. ${ }^{90}$ Eine „arische“ Lebensführung, erklärte Dr. Burg in seinem Vortrag an einem „Heimabend“, gehe über das Erscheinungsbild hinsichtlich Kleidung (laut Burg machten ,Kleider ' keine ,Leute), Körperkonstitution und Benehmen hinaus und schließe ein ideologisches Denken und „rassenmoralisches“ Handeln sowie „arische“ Charaktereigenschaften mit ein:

„Die Frau ist Trägerin, unbewußte Erzieherin eines gesunden Volkes. Darum kann der normale Mensch nie verstehen, warum die Frau das Rührende ihrer Mütterlichkeit durch Eitelkeit, häßliche Verjüngung verwischen will. Übertriebene Äußerlichkeit ist der deutschen Frau so wenig eigen - wird ihr auf die Dauer nie eigen sein. Die Frau besitzt noch nicht Format durch Kleidung - das mag sich auch der Mann gesagt sein lassen - Stil muß der Mensch bewahren, in allen seinen Handlungen - das zeichnet ihn als Rassemenschen aus! Und - jeder muß sich selbst mit diesen Fragen befassen, muß selbst denken, nicht andere für sich denken lassen. Rasse ist Empfindung!!! Wach werden Mädels! In sich selber wach werden! Der Stolz eines deutschen Mädels muß sich rühren! Wir, das deutsche Volk, können durch Lösung dieser Fragen, eine große Nation gründen.“91

Die von ihr geforderte „rassenhygienische“ Lebensführung löst am Ende des Selbsterziehungsromans in Christine kein Unbehagen mehr am Totalitären dieser affirmativen Gefühlspolitik aus. Der emotionspolitische Weckruf „Wach werden Mädels!“ hatte in seiner wissenshistorisch paradoxen Forderung nach selbständigem Denken die Unterdrückung selbstreflektiver Subjektivität zugunsten der totalitären NS-Ideologie zur Folge.

Wie selbst die physische Transformation der jungen Frauen aufgrund ihrer geschlechterspezifischen Aufgaben im „Arbeitsdienst“ bei der Elterngeneration emotionspolitisch aufgenommen werden konnte, zeigt exemplarisch der Brief-

89 Ebd., 88.

90 Vgl. u.a. Scholtz-Klink 1936.

91 Tasche 1935, 33. 
kontakt zwischen Elisabeth Gebensleben-von Alten und ihrer Tochter Irmgard Brester-Gebensleben aus Braunschweig am 17. Juli 1934, etwa zur selben Zeit, als Lisa Tasche ihren „Arbeitsdienst“ verrichtete:

„[...] Heute nachmittag [sic] war Uschi ein paar Stunden da; es war ihr freier Nachmittag. [...] Die Mädels müssen im Arbeitsdienst mächtig ran. Uschi hatte ja auch zunächst trotz reichlicher Verpflegung abgenommen; aber jetzt ist wohl schon ein Stillstand eingetreten [...]. Sie hat richtig braunrot gebrannte Arme, besonders vom vielen Waschen und Trocknen im Freien. Die Mädels waschen die ganze Wäsche aus dem Jungenslager. Uschi hat schon 14 Tage lang, jeden Tag, Waschdienst gehabt, von morgens 5 Uhr bis nachmittags 4 Uhr 14 Tage lang jeden Tag waschen. Jetzt ist Uschi für sechs Wochen lang verantwortliche Leiterin der Küche geworden. Heute hatte sie hundert Stück Grießschnittchen gebacken. Da wird wirklich Arbeiten gelernt! Aber hübsch ist die Kameradschaft unter den Mädels; Uschi hatte so viele fröhliche Bildchen mitgebracht, die im Lager aufgenommen waren. [...]“92

Die bewundernden Worte über die Leistung von Ursula Meyer (1912-1996) ${ }^{93}$ und der Stolz über ihren Aufstieg zur „Leiterin“ überdeckten Gebensleben-von Altens Sorge um „Uschis“ Gewichtsverlust und ihren gravierenden Sonnenbrand. Entscheidend für Gebensleben-von Altens Empfindungen bei ihrer Berichterstattung sind die visuellen Zeugnisse in Form von „fröhlichen Bildchen“, die Uschi verschickte. Diese Propagandaaufnahmen, die im Auftrag des „NS-Arbeitsdiensts“ von Fotografen zahlreich hergestellt wurden, illustrieren die massenpsychologisch wirkungsmächtige Illusion der nationalsozialistischen Gefühlskultur „Kraft durch Freude“ für die Angehörigen und Bekannten zu Hause.

Die Familie Gebensleben ${ }^{94}$ gehörte zu jenem Teil der deutschen Bevölkerung, welche die Machtergreifung Hitlers begeistert begrüßte und darin eine Chance für individuelle Aufstiegsmöglichkeiten und gesellschaftlichen Prestigegewinn innerhalb des bürgerlichen Milieus im Nationalsozialismus erhofften:

„Wir stehen heute noch ganz unter dem Erleben des gestrigen Tages. Immeken, war das ein Tag! Was wir erlebt haben, kann man gar nicht beschreiben. Ein solcher Jubeltag einer Nation kommt wohl ganz selten vor in der Geschichte eines Volkes; ein Tag nationaler Begeisterung, solch aufjauchzender Freude; es ist der Tag, der all das Beste und Heiligste, was im Volke steckt und das in engen Fesseln gelegt war für viele Jahre, nun frei werden ließ und das nun hinausströmt in unbegrenztem Jubel aus tiefster Dankbarkeit. [...] Eben hörte ich die lange Rede Hitlers in der heutigen Reichstagssitzung. Immo, ist das ein Mann! Die ganze

92 Elisabeth Gebensleben-von Alten an ihre Tochter Irmgard Brester-Gebensleben, Braunschweig, 19.07.1934. In: Kalshoven 1995, 237.

$93 \mathrm{Zu}$ Ursula Meyer, vgl. Kalshoven 1995, 488.

94 Vgl. Süß 2018, $109 f$. 
Welt, die über die sogenannte Weltwirtschaftskrise klagt, täte gut, auf diesen Mann, der so überragend ist, zu hören!“ ${ }^{95}$

Als Anhänger der „Deutschen Christen“, eine Bewegung, die 1931 unter Mitwirkung der NSDAP entstanden war, orientierte sich die Familie Gebensleben am „Führerprinzip“ und der NS-Ideologie mit dem Ziel, eine vereinte evangelische Nationalkirche zu schaffen. ${ }^{96} \mathrm{Im}$ rassistischen Glauben an Hitler als ihren ideologischen „Führer“ und an ein „völkisches“ „Deutschtum“ empfanden sie in den Massenkundgebungen um den „Führer“ einen kollektiv erfahrbaren Erlebnisraum in gefühlshistorischer Kontinuität zur christlichen Religiosität, Glaubensgemeinschaft und einer messianischen Heilsbotschaft. Im Gedankengut der „rassenideologischen“ „Gleichschaltung“ verhaftet, befürwortete Frau Gebensleben-von Alten die antisemitischen Verfolgungen der Jüdinnen in einer emotionspolitischen Mischung aus „Freude“ und einem von moralischen Gewissensbissen getragenen, heuchlerischen „Mitgefühl“.97 Dabei drückte sie ihre tiefe Bewunderung für die „Kraft und Überlegung“ aus, die das NS-Regime bei den Gewaltexzessen gegenüber ihren jüdischen Mitbürger`innen an den Tag lege:

„Es gehört schon unendlich Kraft und Überlegung seitens der nationalen Regierung dazu, wenn sie das Trümmerfeld wieder aufbauen will, das ihr die Sozialdemokratie überlassen hat; zunächst ist in Deutschland großes Reinemachen. [...] Es wird vor keinem Halt gemacht [...]. Die Zeit, in der wir jetzt leben, wird wohl erst von der Nachwelt gerecht beurteilt werden. Es ist Weltgeschichte, die wir erleben. Aber die Weltgeschichte geht über das Schicksal des einzelnen hinweg, und das macht diese Zeit, die so erhaben und rein ist in ihrem Ziel, so schwer neben der Freude, das Mitgefühl mit dem Einzelschicksal. Das gilt auch für das Schicksal der Juden, ändert aber nichts an der Beurteilung der Judenfrage als solche. Die Judenfrage ist ebenso eine Weltfrage, wie der Kommunismus, und wenn Hitler damit fertigwerden will, [...], und das Ziel erreicht ist, wird Deutschland vielleicht noch einmal beneidet werden. Die SA-Leute haben vor der Tür des Herrn M. [...] dem Boykott-Tag des Judentums gestanden. [...] ]98

Die emotionspolitische Mobilisierungswirkung, die einen der Söhne Gebensleben-von Altens ergriff, als er sich dafür entschied, der SA beizutreten, zeigt sich auch an der psychopolitischen Entwicklung der autobiografischen Romanfigur Christine.

95 Elisabeth Gebensleben-von Alten an Irmgard Brester-Gebensleben, Braunschweig, 22.03.1933. In: Kalshoven 1995, 182-185.

$96 \mathrm{Zu}$ den „Deutschen Christen“, bezogen auf die Familie Gebensleben, vgl. Kalshoven 1995, 195.

97 Vgl. Elisabeth Gebensleben-von Alten an Irmgard Brester-Gebensleben, Braunschweig, 06.04. 1933. In: Kalshoven 1995, 189.

98 Ebd. 
Christines ideologische Unterwanderung basierte in erster Linie auf der leistungsorientierten Arbeitsideologie „Kraft durch Freude“, die arbeitspsychologisch auf der „völkischen“ „Leistungsauslese“ basierte. ${ }^{99}$ Walter Moede, Lehrstuhlinhaber an der Technischen Hochschule in Berlin, formulierte das Ziel der „Eignungsprüfung“ anlässlich des 25. Jubiläumsjahrs des „Instituts für Industrielle Psychotechnik und Arbeitstechnik“ wie folgt:

„Die Eignung eines Menschen soll als Inbegriff der in der Person vorhandenen Vorbedingungen für ihren erfolgreichen Einsatz in Arbeit und Beruf verstanden werden. Die Eignungsuntersuchungen psychologischer Art, die sich auf Anlage und Befähigung, auf Wesensart und Charakter, insbesondere auf Leistung und Artung des Arbeits- und Berufsträgers beziehen [...]. “100

Dieser totalitäre Anspruch der „Eignungsprüfung“ eines „Volksgenossen“ hinge nicht allein von der „Personalpsychotechnik ${ }^{\text {“101 }}$ ab, sondern stehe im Nationalsozialismus in einem machtpolitischen Abhängigkeitsverhältnis zu „Wirtschaft und Staat“. ${ }^{102}$ Zur „Eignungsprüfung“ setzte die „Personalpsychotechnik“ ähnliche Methoden ein, wie sie von den „Volksgenossen“ in ihrer autosuggestiven „Selbsterziehung“ verlangt wurden. Von einem rassistischen und „typologischen Denken“ geleitet, werden auf der Grundlage von „Gesinnung und Charakter“ sowie „Ausdrucksprinzip, Ausdruckslehre, Ausdrucksproben“ „Berufs- und Leistungstypen“ evaluiert, um das individuelle „Leistungs- und Verhaltensprinzip“ einer Einzelperson prognostizieren zu können, wie bei der Psycho-Physiognomie C.H. Huters gesehen. ${ }^{103}$ Die „Ermittlung der Werte und Triebfedern für Zielsetzung in Beruf und Leben“ war auch das Ziel der nationalsozialistischen Psychotechnik. ${ }^{104}$ Die psychotechnische Methodik, um das „Lebens- und Arbeitsschicksal“ eines Menschen zu bestimmen, basierte auf keiner einheitlichen „Untersuchungsmethodik“. ${ }^{105}$ Als „lebenspraktische Psychologie“ basierte sie lediglich auf der „Erkenntnis der geistig-seelisch-charakterlichen Struktur des

99 Vgl. Lohn und Leistung: Leistungsbezogene Lohnsysteme und Arbeiterbewertungsverfahren. In: Hachtmann 1989, 161-223, $161 \mathrm{f}$.

100 Eignungsprüfung, ihr Standort in Wissenschaft und Gemeinschaft, In: Moede 1943, 1-6, 1. 101 Vorwort. In: Moede 1943, V-VI, VI.

102 Vgl. Eignungsprüfung, ihr Standort in Wissenschaft und Gemeinschaft. In: Moede 1943, 1-6, 1.

103 Vgl. Vom typologischen Denken; Ausdrucksprinzip, Ausdruckslehre, Ausdrucksproben; Leistungs- und Verhaltensprinzip. In: Moede 1943, 74-90, 157-179, 123-156.

104 Vgl. Eignungsprüfung, ihr Standort in Wissenschaft und Gemeinschaft. In: Moede 1943, 1-6, 2.

105 Vgl. ebd., 2ff. 
Berufs als auch des Menschen“. ${ }^{106}$ Ihr „Wahrheitsgehalt“ könne „ausschließlich und allein durch Erfahrungsbeweise erhärtet“ werden. ${ }^{107}$ Diese „Eignungsbegutachtung nach dem Leistungs-Verhaltensprinzip“108 wurde im Rahmen des nationalsozialistischen Selbsterziehungskonzepts von der „deutschen Jugend“ explizit verlangt.

Nach einem Jahr im „Arbeitsdienst“ scheint der emotionspolitische und charakterologische Transformationsprozess mit Hilfe individuell und kollektiv ausgeübter Glückspraktiken für Christine abgeschlossen zu sein: Motiviert durch ihre leistungsorientierte Eigeninitiative, einen „höheren Grad an Persönlichkeitskultur und Leistungsvermögen zu entwickeln, [...] um so ein Höchstmaß an Leistung, Erfolg und Lebensglück zu erreichen“109, übte sich Christine im Sinne von C.H. Huters Ratgeber in autosuggestiver Selbstdisziplinierung im Rahmen einer gemeinschaftsstiftenden Persönlichkeitskultur im „NS-Arbeitsdienst“.

Schümann beschrieb diesen emotionspolitischen Prozess der leistungsorientierten „Selbsterziehung“ anhand des Tagesablaufs in einem „Lager“ der weiblichen NS-Organisationen:

„Geistige Zentren sollen unsere Schulen sein, die unseren Mädeln Rüstzeug geben, die nie Gegensatz sein sollen zu den Schulen des Staates, sondern nur Ergänzung. Jeder Tag in unseren Schulen ist ein Ringen um die Gestaltung und Formung der nationalsozialistischen Gedanken. Das Lied am Morgen, das Hissen der Fahne, das Wort sind Erlebnis, sie geben Richtung für den Tag. Schulung und Sport lösen einander ab. Sprechchor-, Laien-, Stegreifspiel sowie Werkarbeit sind Ausdruck unseres kulturellen Schaffens. Den Abschluss des Tages bildet der Heimabend, der Besinnung sein soll, der zeigt, daß der Tag uns ein Stück weitergebracht hat im Ringen um nationalsozialistische Erkenntnis." ${ }^{\text {"110 }}$

Das „Ringen um nationalsozialistische Erkenntnis“ ist für Christine nach einem Jahr emotionspolitischer Erfahrung im „Arbeitsdienst“ beendet. Gegen die langen Arbeitsstunden rührt sich in ihr kein Widerwille mehr. Auch scheint sie weder Überdruss an den repetitiven und bildungsfernen Arbeitsabläufen noch Müdigkeitserscheinungen aufgrund der körperlich fordernden Arbeit zu verspüren. Stattdessen lässt sie die Leser^innen wissen, dass die „Volksgenossin“ wortwörtlich „Kraft durch Freude“ an der Arbeit schöpfe. Überzeugt vom ideologisch überhöhten Sinn ihrer Arbeit, den sie im Dienst an der „Volksgemeinschaft“

106 Vgl. ebd., 3.

107 Vgl. ebd.

108 Vgl. Wurzelformel der Eignungsbegutachtung nach dem Leistungs-Verhaltensprinzip. In: Moede 1943, 180 - 196.

109 Vgl. Huter 1940, 56.

110 Schümann 1935, 23. 
verrichte, bestärke es ihre Willenskraft und Begeisterung zur „nationalsozialistischen Tat“. ${ }^{111}$

Eine zentrale Bedeutung kam in Tasches emotionspolitischen Schilderungen dem lang ersehnten und dank ideologischer Bekehrung erlebbaren Gemeinschaftsgefühl zu. Besonders am Vorabend von Christines Abreise wird dies nochmals deutlich. Ein letztes Mal versammelt sich die Frauengruppe, in Anwesenheit von Scholz-Klink, im Kreis und singt vor gehisster Fahne ein Lied über das gemeinsam erzwungene „Glück“:

„Frau Scholz-Klink kam. Ehe sie fortfuhr, haben wir einen Kreis um unsere Fahne geschlossen, uns die Hände gegeben - für mich noch einmal, zum letztenmal [sic]. Schwer ist es, hier fortzumüssen. Das habe ich gefühlt, als wir gemeinsam das Lied sangen:

Wir Mädels sind es müde,

Beiseite nur zu stehn,

Wir wolln mit festen Fäusten

Die Räder vorwärtsdrehn [sic],

Nie soll uns unterkriegen

Ein widrig Geschick,

Wir kämpfen und wir siegen,

erzwingen unser Glück!“112

Welche Gemeinsamkeiten und Unterschiede lassen sich zu Fabers Erfahrungsbericht im freiwilligen „Arbeitsdienst“ für junge Männer aufzeigen?

\section{5 „Schippe, Hacke, Hoi!“ Gustav Fabers Erlebnisse aus dem „freiwilligen Arbeitsdienst“}

Fabers Erfahrungsbericht „Schippe, Hacke, Hoi“ erschien 1934 und diente vermutlich als Vorbild für Tasches Erlebnisroman. Dafür sprechen die vom Verlag ähnlich gewählten Titelunterschriften „Erlebnisse, Gestalten, Bilder aus dem freiwilligen Arbeitsdienst“".

Der „Verlag für Kulturpolitik“ bewarb auch Fabers Erlebnisroman mit überschwänglichen Worten:

„Zum ersten Male wird hier die Welt des Arbeitslagerlebens nicht trocken theoretisch erfaßt, sondern erzählerisch lebendig geschildert. Volksecht und unverbildet ist die Schreibweise, von sittlichem Ernst und zugleich von überquellender Heiterkeit durchweht, immer von echter Kameradschaftlichkeit zeugend die packende Schilderung; interessant und voller

111 Vgl. Tasche 1935, Klappentext.

112 Ebd., $281 \mathrm{f}$. 


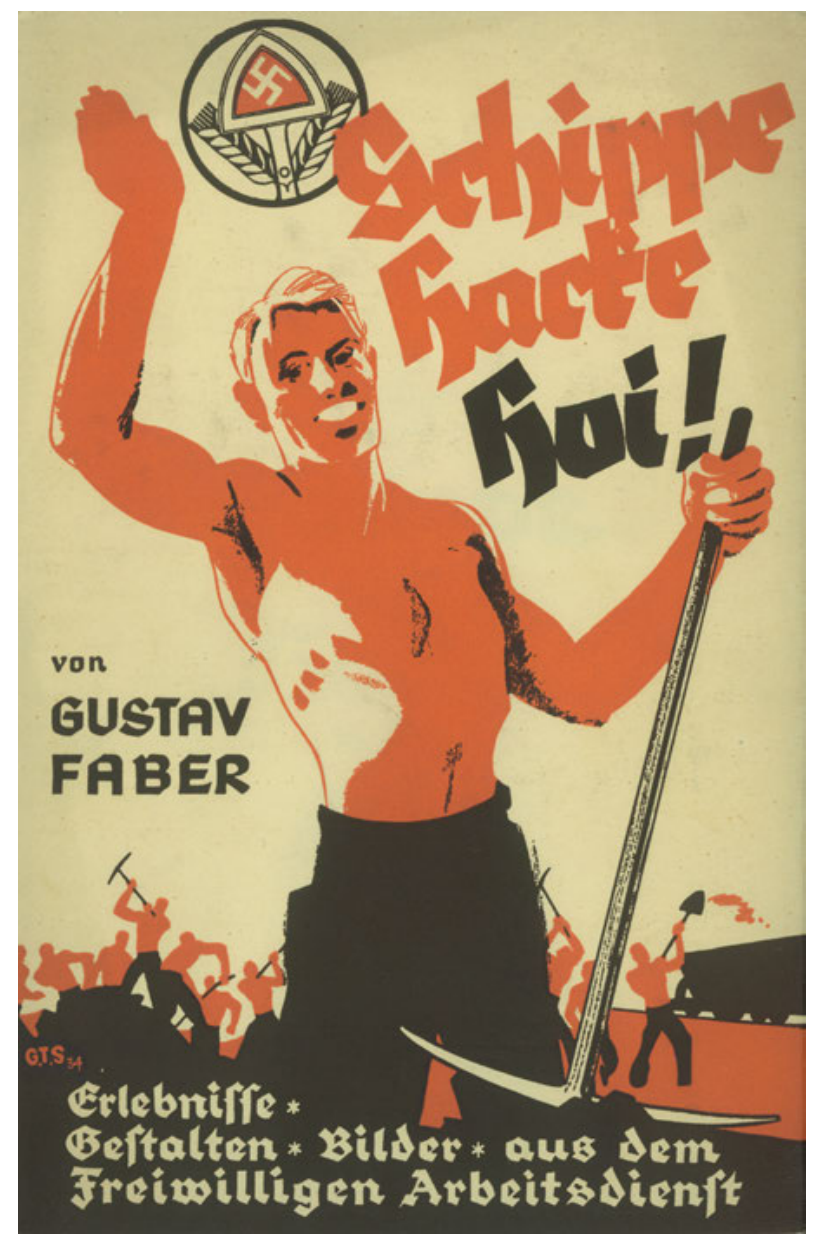

Abb. 10: Gustav Faber, „Schippe, Hacke, Hoi! Erlebnisse, Gestalten, Bilder aus dem freiwilligen Arbeitsdienst“, 1934

Humor die reiche Bebilderung aus der gleichen Hand des Verfassers, eines jungen Studenten und Arbeitsgenoßen. Es ist eine neue Welt, die hier dem Leser in erstaunlicher Ursprünglichkeit entgegentritt und ihn in ihr Dasein reißt. Das Buch wird damit zum maßgeblichen Zeugnis des nationalen und sozialen Empfindens und Denkens einer neuen Jugend, die unsere Zukunft tragen wird. “113

113 Faber 1934, [Klappentext]. 
Freimütig betont der Verlag den Kontext, in welchem der Erlebnisroman eine emotionspolitische Propagandawirkung entfalten sollte. Der Erlebnisroman bilde im Kontext der „,ölkischen Dichtung“ (,[v]olksecht und unverbildet“) die vermeintliche Realisierung der „rassenhygienischen“ NS-Arbeitsideologie und Lebensführung ab. Faber schildere „lebendig“ und mit „überquellender Heiterkeit“ die emotionspolitische Einheit zweier in der Weimarer Republik angeblich noch getrennter Welten: der „proletarischen“ und „bürgerlichen“ Jugend, die als „Werksoldaten“114 im „freiwilligen“ Einsatz des „NS-Arbeitsdiensts“ endlich vereint würden.

Wer war der Autor dieses autobiografischen Romans (Abb. 11)? Im Gegensatz $\mathrm{zu}$ Tasche, deren biografische Lebensdaten ungewiss sind, ist von Gustav Fabers Biografie einiges bekannt. Faber (1912-1993) wurde in Badenweiler geboren. Neben seiner journalistischen Tätigkeit war er vermutlich auch in der Nachkriegszeit bis in die 1990er Jahre ein erfolgreicher Sachbuchautor und Reiseschriftsteller. ${ }^{115}$ Zum Zeitpunkt der Niederschrift seines Erlebnisromans war Faber, wie seine Hauptfigur Paul, Student. Er studierte Geschichte und Germanistik und schloss seine universitäre Ausbildung mit einer Promotion ab. ${ }^{116}$

Paul, die Hauptfigur in Fabers Erlebnisroman, nimmt sich während der Semesterferien eine Auszeit und meldet sich beim „freiwilligen Arbeitsdienst“. Er fährt mit dem Zug nach Herrenstadt in ein „Arbeitsdienstlager“ in der Grenzregion zu Polen, das (wie in Christines Fall) erst kürzlich errichtet worden war. ${ }^{117}$ Nach drei Monaten, am 11. Oktober 1933, endet die offizielle Dienstpflicht für Studenten. ${ }^{118}$ Am Abschiedsabend lässt sich Julius Offenkopp, ein Student der Nationalökonomie und Politik, zu einer emotionspolitischen Rede hinreißen:

„....der Student der Bibliothekwelt, der Student der Lackschuhe und des Tennisschlägers, der Heidelberger Student ist gestorben! ... Es lebt der Student der SA., und er kämpft mit euch!“119

Die emotionspolitische Reaktion der Studenten auf die machtpolitische Auferstehungssemantik des ,neugeborenen“ SA-Manns als ,König‘, in Anlehnung an die Heroldsformel Le roi est mort, vivre le roi, fällt eindeutig gegen das bisherige Leben als Universitätsstudent und für das zukunftsorientierte eines „SA-Kämpfers“ aus:

114 Ebd., 143.

115 Vgl. u.a. Faber 1991.

116 Gemäß Eintrag im Katalog der Deutschen Nationalbibliothek, https://portal.dnb.de/opac. $\mathrm{htm}$ ?method=simpleSearch\&cqlMode=true\&reset=true\&referrerPosition=0\&referrerResultId=per \%3D\%22Faber\%2C+gustav\%22\%26any\&query=idn\%3D131425293, 12.10.2020.

117 Vgl. Faber 1934, 309.

118 Vgl. ebd., 287.

119 Ebd., 288 


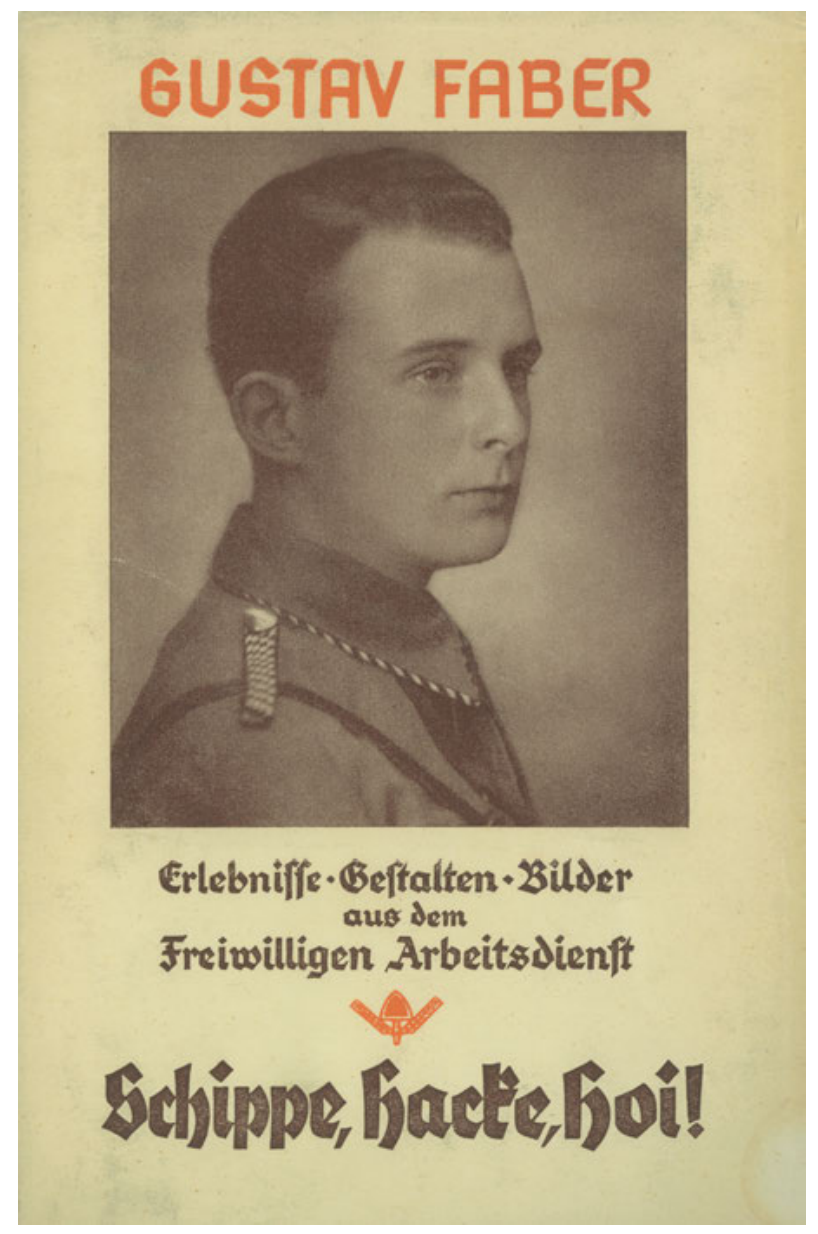

Abb. 11: Gustav Faber, „Schippe, Hacke, Hoi! Erlebnisse, Gestalten, Bilder aus dem freiwilligen Arbeitsdienst“, [Buchrückseite], 1934

„So vermag er es, die Kameraden zu einem Beifallsturm zu bewegen, der alle früheren Dankesbezeugungen übertrifft.“120 Während einige der „Kameraden“ dennoch zur Universität zurückkehren, fährt Paul nach Berlin, wo er sich der SA anschließt. Als Beweggrund für seine Entscheidung nennt Paul eine geschlechterstereotypisierte, „harte, männliche Erkenntnis!“:

120 Ebd., 288. 
„Als anderer Mensch kehre ich zurück. Eine Aufgabe rüttelt auf! Man gehört seinem Volk, dann sich selbst! Das Vaterland ruft! Der Kampf geht weiter. Was wäre der Arbeitsdienst, wenn er im Leben Episode bliebe? Drum denn! Ich kenne meinen Weg! Den will ich weitergehen. Hin zur SA.! Ein neues Leben in Berlin!““121

Wie ein Schauspieler, der die Bühne für den nächsten Akt betrete, wolle Paul sich der nächsten „Episode“ seines Lebens zuwenden. ${ }^{122}$ Der Ausgang des nationalsozialistischen ,Dramas' und die ,Rolle‘, die er darin spiele, sei für Paul bereits vom NS-Regime vorherbestimmt und nicht länger in seiner Entscheidungsgewalt: „Es kommt mir nicht vor, als verlasse ich ein Schauspiel mitten in seiner Handlung oder bei seinem Höhepunkt, sondern während seines letzten Auftritts. “123

An den Erzählsträngen über Offenkopps und Pauls NS-ideologische Radikalisierung läßt sich ein wesentlicher Unterschied zwischen der weiblichen und männlichen Erzählsituation der beiden autobiografischen Erlebnisromane Tasches und Fabers aufzeigen: Paul ist sich bereits beim Antritt des „NS-Arbeitsdiensts“ seiner ideologischen Gesinnung sicher und erlebt im „Arbeitsdienst“ eine emotionspolitische Radikalisierung. Das von der Partei geforderte Gemeinschaftsgefühl muss Paul nicht erst selbstkritisch ergründen, wie es bei Christine der Fall war. Paul verspürt angeblich augenblicklich ein ideologisches Zusammengehörigkeitsgefühl, als er auf einen seiner neuen „Kameraden“ trifft:

„Wir geben uns die Hände, der lange Blonde und ich. Er ist der erste Arbeitsgenosse, den ich treffe. [...] wir [kennen] uns schon näher, als man es nach den paar Worten annehmen sollte. In uns beiden lebt dieselbe Erwartung. Derselben Zukunft fahren wir entgegen. Gemeinsames Schicksal bindet.“124

Wie erklärt sich Paul seine emotionspolitische Intuition? Er glaubt, dieselbe ideologische Gesinnung im Gegenüber zu fühlen. Dieses Gefühl der ideologischen und rassistischen Gemeinschaft schließe ein „unsichtbares Band“125 der Verbundenheit um sie herum, womit sich Faber derselben Metapher bedient wie Tasche, um das gemeinschaftsstiftende Zusammengehörigkeitsgefühl $\mathrm{zu}$ beschreiben.

Im Vergleich fallen weitere Metaphern auf, die beide Autor^innen mit demselben Sinngehalt verwenden. Ein einschlägiges Beispiel ist die „Sonne“, die als Sinnbild „der Größe und der Ehre über Deutschland glüht“ und das Schicksal

121 Ebd., $317 \mathrm{f}$.

122 Vgl. ebd., 309.

123 Ebd., 309.

124 Ebd., 33.

125 Vgl. ebd., 71. 
„Deutschlands [...] und das jener tausend anderer letzte Erfüllung“ symbolisiere. ${ }^{126}$ Die Verwendung derselben Sprachbilder ist ein Indiz dafür, dass dieser emotionspolitisch konnotierte Sprachgebrauch in der Propaganda des „NS-Arbeitsdiensts“ geschlechterübergreifend geltend gemacht wurde. Auch die Freizeitorganisation „Kraft durch Freude“ verwendete in ihrem Bildband „Unter dem Sonnenrad. Ein Buch von Kraft durch Freude“ die „Sonnen“-Metapher als Symbol ihrer affirmativen Gefühlspolitik. ${ }^{127}$

Ein weiterer Unterschied zu Tasche zeigt sich in Pauls klarer Vorstellung von seiner zukünftigen nationalsozialistischen Lebensführung. Sein Werdegang mit „Führeranspruch, gebunden an Leistung“, wie es Will Decker programmatisch in seiner Schrift „Die politische Aufgabe des Arbeitsdienstes“ (1935) definiert, schien für Paul innerhalb des NS-Gesellschaftssystems vorherbestimmt. ${ }^{128}$ Decker erläutert das Prinzip des „Führertums“ im „Arbeitsdienst“, in Referenz an Hitlers Konzept eines „Führer[s] [...], der als Politiker und als Mensch seine ganze Person in den Dienst der Idee stellte“, wie folgt:

\footnotetext{
„In der Person des Reichsarbeitsführers ist der Typ verkörpert, den er fordert als Erziehungsergebnis des Arbeitsdienstes, jener neue deutsche Menschentyp des ,Arbeitsmannes', der für das zukünftige deutsche Leben ein ebenso fester Begriff werden soll wie es für den Engländer der ,gentleman` ist. Dieser Typ geht auf drei Wurzeln zurück: Arbeitertum, Bauerntum, Soldatentum. Diese drei Wurzeln unseres völkischen Lebens ergeben den neuen Menschentyp, wenn ihr Wachstum bestimmt wird von den drei Gesetzen, die der Reichsarbeitsführer wiederum nicht nur für den Arbeitsdienst als Lehre aufgestellt, sondern in seinem eigenen Leben und in der Gestaltung des Arbeitsdienstes selbst gelebt hat: Treue, Gehorsam, Kameradschaft." ${ }^{129}$
}

Anders als der von Decker entworfene Antagonist eines elitär-bürgerlichen und intellektuellen Studenten ${ }^{130}$, betonte der Student Paul die kameradschaftliche Verbrüderung der Gesellschaftsschichten im utopischen Konzept der „Volksgemeinschaft“. Jene Studenten, die sich in der gemeinsamen Arbeit mit „den deutschen Arbeitern“ ihre Hände in den Stollen nicht schmutzig machen wollten, sondern ausschließlich als „Erzieher“ Befehle erteilten, verachtete Paul zutiefst. „Der Arbeitsdienst ist Ehrendienst!“, erklärt Paul während der Zugfahrt einem

126 Vgl. ebd., 91, 286, vgl. Tasche 1935, 276.

127 Vgl. Busch 1938.

128 Vgl. Decker 1935, 11.

129 Ebd., 12.

130 Zur Stereotypisierung des den „Arbeitsdienst“ verweigernden „bürgerlichen“ Studenten im Vergleich zur vorbildhaften Einstellung des „strebsamen Malergesellen“ bei Decker vgl. Decker 1935, $8 \mathrm{ff}$. 
Mathematikstudenten im 6. Semester. Für diesen wurde die „studentische Dienstpflicht“ zu spät eingeführt. Er denkt jedoch nicht im Traum daran, dem „freiwilligen Arbeitsdienst“ beizutreten. ${ }^{131}$

Der folgende Dialog deckt die ideologische Diskrepanz zwischen den beiden Studenten auf. In der Diskussion wird die ambivalente Kontinuität jenes arbeitspsychologischen Glückswissens offensichtlich, welches eine wissenshistorische Transformation vom leistungsorientierten Erfolgstypus der Weimarer Republik zum nationalsozialistischen Erfolgstypus als rassistischem Führungstypus durchlief:

„[Der Mathematikstudent:] ,Was heißt hier [innere] Pflicht? Da gibt es genug junge Leute, die auf der Straße stehen, die nichts zu tun haben: Für diese ist der Arbeitsdienst [...]. Durch die Freiwilligkeit eines einzelnen wird Deutschland bestimmt nicht saniert.‘

,Das glaube ich auch. Aber wenn wir alle zusammenstehen, alle zusammenhalten; wir Studenten und Arbeiter, die ganze Jugend...

,Arbeiter? Arbeiter? Was gehen mich die Arbeiter an? Jeder besorge sein eigenes Haus! Wir sind zunächst Studenten! Unser Arbeitsdienst ist auf der Universität!

,Aber wofür arbeiten Sie denn auf der Universität? Für ihr eigenes Wohl? Als Selbstzweck? Oder für Ihr Volk? Das war immer ein Fehler des Akademikers, daß er den Anschluß an die Gedanken- und Gefühlswelt des arbeitenden Volkes versäumte. Wen ich nicht kenne und schätze, mit dem kann ich auch nicht zusammenarbeiten! Nur aus Tat und Verzicht wachsen Führer! [...] Wir haben uns diese Position zu erkämpfen. [...]"

[...] ,Das klingt alles schön und richtig. Doch als Student habe ich zunächst die Pflicht, mich auszubilden. Meinen Eltern, die mir meine Laufbahn ermöglichen, muß ich mich durch Erfolg dankbar erweisen.

,Recht so! Aber zunächst stehen Sie zur Rechenschaft vor Ihrem Volk! [...] Das lebensferne Bücherwissen ist wertlos, wenn es nicht durch Einfühlung und Einfügung in die Geschehnisse des tatsächlichen Lebens Sinn und Berechtigung erhält!““132

Aufschlussreich an diesem Dialog ist, dass sich die Studenten nicht in erster Linie über die antisemitische „Gleichschaltung“ der „Volksgemeinschaft“ streiten (diese kommt gar nicht zur Sprache), sondern über die Frage nach den gesellschaftlichen „Verteilungs- und Machtfragen“133 in der nationalsozialistischen Gesellschaftsordnung: „Man gehört seinem Volk, dann sich selbst“, lautet Pauls Devise. ${ }^{134}$ Pauls Rhetorik des inneren Pflichtbewusstseins einer nationalsozialistischen Sozialpolitik bestimmt im Interesse des Autors, beziehungsweise der

131 Vgl. Faber 1934, $25 \mathrm{f}$.

132 Ebd., $25 \mathrm{f}$.

133 Vgl. Süß 2018, 111.

134 Vgl. Faber 1934, 317. 
selbstdisziplinarischen NS-Arbeitsmoral, den Ausgang der Argumentation. ${ }^{135}$ Und doch scheint Paul eines nicht zu merken: Die Betonung der leistungsorientierten Selbstoptimierungskultur als nationalsozialistische Körperpraktik einer „Auslese“ wurde aus der Arbeitspsychologie der Weimarer Republik in den Kontext der NS-Arbeitspolitik transferiert. In arbeitspsychologischer Wissenskontinuität zur psychotechnischen „Menschenauslese“ heißt es auch bei Decker: „So gingen wir an die Arbeit der Führerauslese und Führererziehung die für alle Zeiten an entscheidenster [sic] Stelle in der Reihe unserer Aufgaben stehen wird. "136 Der leistungsorientierte Erfolgstypus, wie er in den arbeitspsychologischen Studien und Ratgebern charakterologisiert und im Nationalsozialismus „rassenideologisch“ als Ariertypus überhöht wurde, entspricht exakt Pauls „[v]olksechte[r]“137 „Selbstbetrachtung“138 auf seinem (Selbst-)erziehungsweg ins nationalsozialistische „Glück“. ${ }^{139}$ Der wissenshistorische Unterschied ist jedoch, dass sich der Student Paul explizit gegen den Habitus eines angeblich bürgerlich-kapitalistischen Elitarismus (Stichwort: leistungsorientierter „Auslese“) zur Wehr setzt eine Polemik, die aus heutiger Sicht erschreckend zeitgenössische Züge trägt. Vermutlich war Paul vom NS-Regime bereits darüber informiert worden, dass der gesellschaftliche Überlegenheitsduktus der Bürgerlichen nach der „Gleichschaltung“ aus Sicht eines SA-Funktionärs aufgrund seiner totalitären Machtposition gegenüber jedem „Volksgenossen“ obsolet würde.

Am Beispiel des Studenten Offenkopp wird den Leser^innen im Rahmen des nationalsozialistischen Erziehungskonzepts exemplarisch aufgezeigt, wie sich eine charakterologische Transformation eines stereotypisierten Berliner „Stadtmensch[en]“ durch die selbstdisziplinarische und leistungsorientierte Erfahrung in der „NS-Arbeitsgemeinschaft“ vollzöge. Bei ihrer ersten Begegnung wurde Offenkopp von Paul abschätzig als „Stadtmensch“ charakterisiert: „[...] in keinerlei natürlicher Beziehung zur Erde und zum Gebirge, wenngleich man ihn noch lange nicht jenem Asphalt beiordnen kann, der sich in fader Äußerlichkeit, in nichtiger Form und Mode erschöpft. “ ${ }^{140}$ Dieser charakterologisch als „,begabt und praktisch veranlagt [...], [1]eicht ironisch“ beschriebene Student erlangte im Zuge seiner ideologischen Radikalisierung eine „Führerrolle“ im „Arbeitsdienstlager“.

135 Bei Decker heißt es pathetisch: „Die heldische Sachlichkeit einer neuen Zeit sammelte jene Männer, die in einer verschworenen Gemeinschaft zu verwirklichen begannen, was der Führer dem deutschen Volke schenkte: nationalen Sozialismus“. Vgl. Decker 1935, 23.

136 Vgl. Decker 1935, 16.

137 Faber 1934, [Klappentext].

138 Langenbucher 1933, $21 \mathrm{f}$.

139 Vgl. Rinne 1941.

140 Vgl. Faber 1934, 95. 
Offenkopp wird die begehrte „Schulungsleitung“ anvertraut, welche die Gestaltung der Nachmittagsvorträge, die abendlichen „Arbeitsgemeinschaften“ sowie die „Freizeitgestaltung“ umfasst:

„Sofort zieht er begabte Kameraden für das bedeutungsvolle Arbeitsgebiet als Mitarbeiter bei. Die Freizeitgestaltung übernimmt Kamerad Jaschek. Jaschek teilt diese wiederum ein in: Lesestunde, Singstunde, kurzschriftliche Übungen, Spielabend. - Die Nachmittagsvorträge behält sich zunächst Offenkopp vor. Im Lager ist er von nun an ,Der Mann“.“"141

Wie zeichnet sich Fabers Erzählstil im Vergleich zu Tasches aus? Faber und Tasche verwenden ähnliche Erzähltechniken, um die Leserschaft von ihren Glückserlebnissen im „NS-Arbeitsdienst“ zu überzeugen. Faber schreibt jedoch nicht als auktorialer Erzähler, sondern in der Erzählform eines Ich-Erzählers. Die Erfahrungen des erlebenden und narrativen Ichs überlagern sich, sodass der Erzähler selbst zum Objekt der Narration wird. Auf diese Weise erzeugt der Autobiograf eine noch subjektivere Erzählsituation als es bei Tasche der Fall ist. Die Gedanken und Empfindungen der Hauptfigur werden unmittelbar wiedergegeben. Der IchErzähler bei Faber führt seine Hauptfigur, anders als Tasche, zu Beginn des Erlebnisromans nicht ein. Nur beiläufig erfahren die Leser^innen in der Mitte der Erzählung aufgrund eines Zurufs, dass der Protagonist und Ich-Erzähler Paul heißt. ${ }^{142}$ Die begrenzte Erzähltechnik hat zur Folge, dass sowohl bei Faber als auch bei Tasche ein Mangel an dramaturgischen Spannungsbögen festzustellen ist. Im Unterschied zu Faber gelingt es Tasche jedoch, mit ihrer auktorialen Erzählerstimme eine distanziertere Erzählsituation zu kreieren und dadurch eine zusätzliche Reflexionsebene zur Verbreitung der NS-Propaganda einzubauen.

Welche emotionspolitischen Strategien und Mechanismen wendet Faber an, um die Wirkungsmacht einer affirmativen Gefühlspolitik literarisch darzustellen?

Die „Verhaltenslehre der kalten persona“, wie sie vom Kulturwissenschaftler Helmut Lethen für die Literatur der „Neuen Sachlichkeit“ beschrieben wurde, geht von einem gefühlskalten Menschentypus aus, der sich aus einer „sozialen Desorientierung“ und einem demütigenden Schamgefühl aufgrund der Niederlage im Ersten Weltkrieg entwickelt habe: „Sechs Millionen demobilisierte Deutsche müssen in zivilen Institutionen aufgefangen, 2,7 Millionen Kriegsinvalide versorgt werden. ${ }^{\text {" }}{ }^{43}$ In Analogie zum arbeitspsychologischen und leistungsorientierten „Motor-Mensch“-Modell trügen die neusachlichen Romanfiguren der

141 Ebd., 146.

142 Vgl. ebd., 166.

143 Lethen 2014, 7. 
Nachkriegszeit „Masken“, unter denen sie als eine Art emotionspolitischem Schutzmechanismus ihre authentischen Gefühle und insbesondere ihre wahren „Charaktere“ gegenüber der als feindlich wahrgenommen Außenwelt verbargen. ${ }^{144}$ Dieser emotionspolitische „Habitus der Kälte“, der nach Helmuth Plessner (1892-1985) mit einem Verlust eines echten Gemeinschaftsgefühls und nach Elias Canetti (1905-1994) mit einer Flucht in die „Verhaltensform in der Masse“145 einherginge, hätte sich als „Selbstinszenierun[g] eines Lebensstils“146 bis in die Zeit des Nationalsozialismus ausgewirkt, so Lethen. ${ }^{147}$ Als Gegensatz zur „kalten persona“ galt für Lethen die sogenannte „Kreatur“: „Mit ihr wird der Anspruch auf eine selbstbestimmte Lebensführung aufgegeben. “148

Entgegen Lethens These ist der emotionspolitische Habitus der nationalsozialistischen Hauptfiguren Paul und Christine ambivalent. Neben erkennbaren Eigenschaften einer „kalten persona“, zu denen auch ein „Zug ins Heroische“149 zählt, sind ihre Wortwahl und Empfindungen gerade nach außen affirmativemotional. Die literarische Darstellung Fabers kreiere, laut dem „Verlag für Kulturpolitik“, eine emotionale Spannbreite zwischen „sittlichem Ernst“ und „überquellender Heiterkeit“, die das nationalsozialistische „Empfinden und Denken [...]“ der „neuen Jugend“ im Sinne der NS-Literaturpolitik pointiert darstelle. ${ }^{150}$ Aus diesem Grund wurden gegen „die Herausgabe dieser Schrift“ seitens der NSDAP auch „keine Bedenken erhoben“, wie es der „Vorsitzende der Parteiamtlichen Prüfungskommission zum Schutze des NS-Schrifttums“ am 3. August 1934 beglaubigte. ${ }^{151}$

Es wäre jedoch weit verfehlt von einem emotionspolitischen Habitus der Demaskierung als einem Teil einer nationalsozialistischen Glückspraktik zu sprechen. Dafür war die selbstdisziplinarische Gefühlspolitik der arbeitsideologischen „Kraft-durch-Freude“-Dogmatik zu restriktiv, wie es das Beispiel Christines zeigt. Wollte man den Gedankengang Lethens weiterführen, so ließe sich der nationalsozialistische Habitus der Aktivist*innen als eine affirmative „Persönlichkeitskultur“ (C.H. Huter) im „NS-Arbeitsdienst“ beschreiben. Die porträtierten

144 „Das neusachliche Jahrzehnt erstaunt mit Bildern, die den Menschen als Bewegungsmaschine, seine Gefühle als motorische Gebaren und die Charaktere als Masken wahrnehmen.“ Lethen 2014, 10.

145 Lethen 2014, 38.

146 Ebd., 12.

147 Vgl. ebd., 7-12.

148 Ebd., 12.

149 Lethen 2014, 35.

150 Vgl. Faber 1934, [Klappentext].

151 Vgl. ebd., [2]. 
Frauen waren Träger^innen einer emotionspolitisch ambivalenten „Maske“ eines „glücklichen“ „Ernsts“152. Masken trugen sie allemal, wie Christines Psychogramm zeigt. Trotzdem wollte die Autobiografin am Ende des Erlebnisromans die Leserschaft eines Besseren belehren, indem sie die emotionspolitische Einheit aus Erleben und Fühlen betonte.

Die Hauptfiguren Christine und Paul als willenlose „Kreaturen“ zu bezeich-

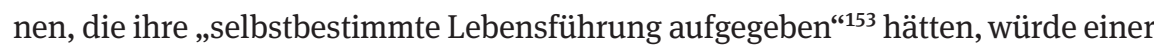
Absolution gleichkommen. Es würde die jungen Hauptfiguren und zugleich ihre Autobiograf*innen von der moralischen Verantwortlichkeit ihres Handelns freisprechen, was angesichts der individuellen emotionspolitischen Selbsterziehungspraktik nicht zutrifft.

Das folgende Beispiel soll die ambivalente Männlichkeitsdarstellung in Fabers nationalsozialistischem Erlebnisroman veranschaulichen. Dabei geht die Untersuchung von der These aus, dass durch die literarische Darstellung - insbesondere affirmativer Gefühlserlebnisse - ein höherer Grad an emotionspolitischer Identifikationsmöglichkeit für die Leserschaft geschaffen wurde, als es eine einseitig polemische „Blut-und-Boden“-Literatur erreichte. ${ }^{154}$

Zu Beginn des Romans beschreibt der Ich-Erzähler die vor seinem Zugfenster vorbeiziehende Landschaft. Die in Paul aufsteigenden rührseligen Empfindungen angesichts der Wiesen und Täler erinnern an Heimat- und Landromane, die sentimentale Empfindungen beschreiben. Gefühlsbetont sind ebenfalls Pauls Schilderungen seiner patriotischen Liebe zum männlich konnotierten Vaterland, welche die Fahrt durch die „deutsche“ Landschaft in ihm auslöst. Paramilitärische Gedankengänge über Soldatentum und NS-ideologisch konnotierte Gefühle von Arbeitswillen und Kampfeslust überwältigen Paul, wenn er, nahe der polnischen Grenze, in militärische Expansionsfantasien verfällt. Gegenüber „Deutschland“, als weiblich konnotierter Heimat, hegt der junge Mann wiederum zärtliche Gefühle wie zu einer Geliebten. Zudem spürt er ein Gefühl von Sicherheit und Geborgenheit, wenn er an sein Heimatland denkt. Faber wählt eine metaphorische Sprachweise, die an das „rassenhygienische“ Idealbild einer umsorgenden, „deutschen Mutter“ erinnert (s. Kap. 14). ${ }^{155}$

Neben seinen Empfindungen sind Pauls Erlebnisse und Erfahrungen in einer ambivalent gefühlsbetonten Sprache verfasst. Da wäre Pauls scharfe Rhetorik zu nennen, die in ihrem polemischen Absolutheitsanspruch einer nationalsozialis-

152 Vgl. ebd., [Klappentext].

153 Lethen 2014, 12.

154 Diese Wirkungsrezeption zeigte bereits Adam in seiner Untersuchung exemplarisch auf. Vgl Adam 2010.

155 Vgl. Faber 1934, 15-33. Zur NS-Rezeption der deutschen Romantik vgl. Klausnitzer 1999. 
tischen Weltanschauung keinen Spielraum für ambivalente Diskursivität zulässt. Stattdessen diskreditiert er diese bei seinen studentischen „Kameraden“ als bürgerliche Schwäche und Verminderung der Lebensfreude. So urteilt er über den Mathematiker, den „liberalen Freistudent[en]“, der einer „vergangenen Zeit“ angehöre: „Frei: Ohne Gesinnung, ohne Lebensanschauung, ohne Pflichten und Verpflichtungen und daher auch ohne Kraft, Freude und Einsatz!“156

Diese ambivalenten Gefühlseindrücke, die der nationalsozialistische Männlichkeitstypus der „Prüfungskommission zum Schutze des NS-Schrifttums“ zufolge durchaus empfinden durfte, werden in Hitlers Rede an die „Hitler Jugend“ auf dem „Reichsparteitag“ 1935 problematisiert. Mit dem Titel „Dafür seid ihr verantwortlich!“ stellt er den Wandel der Gefühlspolitik der Jugend in einen geschlechterpolitischen und rassistischen Kontext. Hitler mahnt seine Hörer`innen von „über 45000 Vertreter[n]“ eindringlich, sich vom Männerbild der Weimarer Republik zu trennen und sich selbst zu einem „neuen Menschen“ zu erziehen. Wie diese „neuen Menschen“ lernen sollten, emotionspolitisch zu empfinden, um entsprechend der nationalsozialistischen Lebensführung $\mathrm{zu}$ handeln, schildert Hitler im paramilitärischen Erziehungston:

\begin{abstract}
„[...] Heute, da sehen wir mit Freude nicht mehr den bier- und trinkfesten, sondern den wetterfesten jungen Mann, den harten jungen Mann. Denn nicht darauf kommt es an, wieviel Glas Bier er zu trinken vermag, sondern darauf, wieviel Schläge er aushalten, nicht darauf, wieviel Nächte er durchzubummeln vermag, sondern wieviele Kilometer er marschieren kann. Wir sehen heute nicht mehr im damaligen Bierspießer das Ideal des deutschen Volkes, sondern in Männern und Mädchen, die kerngesund sind, die straff sind. [...] Wir müssen einen neuen Menschen erziehen, auf daß unser Volk nicht an den Degenerationserscheinungen der Zeit zugrunde geht. [...]“157
\end{abstract}

Hitlers Ideal eines „Werksoldaten“158 war kein „bier- und trinkfeste[r] Bursche“, wie es sie angeblich nur zur Zeit der Weimarer Republik gegeben hätte. Hitler brauchte junge Männer, die sich mit Hilfe emotionspolitischer Selbstdisziplinierungspraktiken auf einen baldigen Kriegseinsatz vorbereiten. Derselbe Anspruch autosuggestiver Selbstdisziplinierung galt auch für junge Frauen, die Hitler in seiner Rede infantilisierend als „Mädchen“ bezeichnete. In seiner Erziehungsanleitung zur „Rassenmoral“ umschrieb Hitler den (para-)militärisch-selbsterzieherischen Befehl an die Jugend wie folgt:

156 Vgl. Faber 1934, 28.

157 Hitler 1935, 7.

158 Faber 1934, 143. 
„[...] Wir sind eine Gefolgschaft, aber wie das Wort schon sagt, Gefolgschaft heißt folgen, heißt Gefolgschaft leisten. Unser ganzes Volk müssen wir erziehen, daß immer, wenn irgendwo einer bestimmt ist, zu befehlen, die anderen ihre Bestimmung anerkennen, ihm zu gehorchen, weil schon in der nächsten Stunde vielleicht sie selbst befehlen müssen, und es genau so nur dann können, wenn andere wieder Gehorsam üben. Es ist der Ausdruck eines autoritären Staates, bei dem jeder Stolz ist, gehorchen zu dürfen, weil er weiß: ich werde wenn ich befehlen muß, genau so Gehorsam finden. [...] wir sind ein Volk das von klein auf lernt, diszipliniert zu sein." ${ }^{159}$

Hitler entwirft in seiner Rede eine Erziehungspolitik der Gehorsamkeit und des Führungswillens, wie sie auch Rinne in den Leitsätzen seines Glücksratgebers für eine nationalsozialistische Lebensführung vorgab. Die autobiografische Romanfigur Paul folgte diesem Apell. Er war ein Prototyp dieser ambivalenten Doppelrolle aus opferbereitem Diener für Hitler und einem Führungstypus, der wiederum Anderen als Vorbild diente. Diese ideologische Doppelrolle nahm Paul für die Leser*innen ein, um sie in einer autosuggestiven Wiedererkennung zu emotionalisieren und zur Nachahmung zu mobilisieren. ${ }^{160}$

Die totalitäre Handlungs- und Gefühlsspirale, welche in Gewalt, Massenmord, Angst und Terror münden sollte, durchdrang im Nationalsozialismus sowohl die Wissenschaft, Ratgeberliteratur, Körperkultur, Erziehung, Bildung, Künste als auch die Berufs- und Partnerwahl. ${ }^{161}$ Dabei besaßen angeleitete Gefühlspraktiken eine entscheidende Bedeutung. Der autoritären Forderung Hitlers sollten sämtliche „Volksgenossen“ in ihrem individuellen Selbstdisziplinierungsprozess aus einem inneren, „rassenmoralischen“ Pflicht- und Ehrgefühl heraus Folge leisten.

Fabers Erlebnisroman illustriert diese Politik einer nationalsozialistischen Gefühlskultur eindrücklich. Die bei Faber beschriebenen affirmativen Gefühlsausbrüche prägen maßgebend die Handlungsweisen des Protagonisten sowie die seiner „Kameraden“. Denken, Handeln und Fühlen verschmelzen im Sinne der nationalsozialistischen Gefühlspolitik zu einer totalitären Lebensführung. Exemplarisch dafür steht Pauls eschatologisch anmutendes Glücksfühl, als „Werksoldat“ im „Arbeitsdienst“ aktiv werden zu können: „Willensfreudig! Willensfrei!“"162 bezeichnet er diesen emotionspolitischen Willensakt, der aus heutiger Sicht lakonische Züge trägt. Entsprechend lautet Deckers emotionspolitisches

159 Hitler 1935, 8.

160 Mehr zur wissenshistorischen Rezeption von Theatertheorien im Nationalsozialismus s. Kap. 15.

161 Zur Partnerwahl als Teil der „rassenhygienischen“ Gefühlskultur im Nationalsozialismus s. Kap. 14.

162 Vgl. Faber 1934, 20. 
Selbsterziehungskonzept zur „Heranbildung des Führernachwuchses im Arbeitslager“ zwei Jahre später:

„Wir gehen heute - nach vollzogenem Aufbau der Organisation - von dem Grundsatz aus, daß jeder Führer des Arbeitdienstes aus der Front hervorgehen muß, aus der Gemeinschaft und der praktischen Arbeit im Lager aufsteigen muß zu dem Platz, den auszufüllen er befähigt und berufen ist. Nur wenn in ihm selbst das nationalsozialistische Erlebnis der Arbeits- und Lebenskameradschaft im Lager wirksam geworden ist, wird er es denen, derer Führer er sein will, richtig vermitteln können." ${ }^{\text {163 }}$

Zu Pauls „nationalsozialistische[m] Erlebnis der Arbeits- und Lebenskameradschaft im Lager“ zählt auch sein dynamischer Tatendrang, aus rassistischem Ehrgefühl und „Stolz“ heraus den „Arbeitsdienst“ zu leisten. Paul schöpfte „Kraft durch Freude“ an der nationalsozialistischen Tat. Leistungsorientiert wie Paul sich gab, trug sein „Wille“ zum paramilitärischen Handeln bei. Dabei empfand er sich „rassenideologisch“ als Teil einer wiedervereinten „Volksgemeinschaft“:

„Wo liegt nun eigentlich der Unterschied zwischen diesen Schlesiern, Pommern, Märkern und mir, dem Süddeutschen! Ich finde ihn nicht! Nicht mehr! Die heutige Zeit kennt einen Willen, einen Ernst, eine Freude. Wir alle finden uns in Kameradschaft und Gefolgschaft, in den gleichen Zielen und im Stolze, Deutscher und von demselben Blute zu sein!“‘164

Offenkopp formuliert es in einer Rede „Von der Arbeit und der Berufsehre. Von Berufsfreude und Berufsstolz“ wie folgt:

„Ihr alle seid Teile einer Gemeinschaft: Einer Familie, einer Gemeinde, eines Volkes. Unsere Gemeinschaft im Arbeitsdienst ist eine soldatische. Eure Tugenden sind die des Soldaten: Zucht, Verantwortungsgefühl, Schweigen, Gehorsam, Zähigkeit, Verzicht, Ordnung und Unterordnung unter einen Willen. Arbeit ist nicht Zwang. Arbeit ist sinnvolle Aufgabe. Ich weiß, daß ihr diese Aufgabe fühlt. Euer Gefühl ist Begeisterung, und Begeisterung braucht keinen Zwang! [...] Der Sieg ist unser! Habt diesen Sieg als festes Ziel im Auge, dann wird der Erfolg euer sein! Die Gewissheit tragen wir in unseren Herzen: Es muß aufwärts gehen! Wir stehen in der Zeit freudigen Erwachens! Wir gehen einen sicheren Weg. Ein gottgesandter Führer führt Deutschland. Uns geht ein Führer voran! Wir folgen dem Führer! Was er auch befiehlt! Kameraden! [...]“165

Die Semantik der Kameradschaft und Gefolgschaft im „Arbeitsdienstlager“ war ein Sinnbild für die „gleichgeschaltete Volksgemeinschaft“. Dieser Semantik lag

163 Decker 1935, 16.

164 Faber 1934, 22.

165 Ebd., $144 \mathrm{f}$. 
der emotionspolitische Appell zugrunde, „dem Führer“ in den sicheren Tod des Zweiten Weltkriegs zu folgen.

Die handlungsanweisenden affirmativen Gefühlsbeschreibungen bei Faber und Tasche verfolgten unterschwellig dasselbe ideologische Erziehungsziel: Diese Gefühlspraktiken sollten dem Leser suggerieren, dass sie einem moralisch integren und rechtschaffenen Charakter und Menschentyp entsprungen seien, der nach bestem Wissen und Gewissen handle.

Die Bedeutung der „Rassenmoral“ zur Legitimation der nationalsozialistischen Lebensführung erläuterte Hitler in der oben zitierten Rede wie folgt:

„[...] Wenn wir so dem deutschen Volke den Lebensweg zeichnen und festlegen, dann wird, glaub ich, auch in anderen Völkern das Verständnis für eine so anständige Gesinnung allmöglich kommen und wachsen, und man wird uns vielleicht da und dort aus diesem inneren Verständnis heraus brüderlich die Hand reichen. Nie aber wollen wir vergessen, daß Freundschaft nur der Starke verdient, und der Starke gewährt. Und so wollen wir uns denn stark machen, das ist unsere Losung! Und daß dieser Wunsch in Erfüllung geht, dafür seid ihr mir verantwortlich. Ihr seid die Zukunft der Nation, die Zukunft des Deutschen Reiches!“166

Hitler überträgt den Jugendlichen rhetorisch die Verantwortung für das Schicksal einer ganzen Nation. Ihr „Lebensweg“ mündete zynischerweise nicht im „Glück“, sondern im Zweiten Weltkrieg.

\subsection{Glückserlebnisse im „Arbeitsdienst“: Eine „volkshafte Dichtung“6}

Vor diesem wissenshistorischen Hintergrund sind Tasches und Fabers autobiografische Schilderungen ihrer Glückspraktiken weder originell noch von literarischer Qualität. Das brauchten sie im Rahmen der „volkshaften Dichtung“ nach Langenbucher auch gar nicht zu sein. Dieser forderte eine „deutsche Dichtung“, die aus dem „heldischen Lebensgrunde“ der Autor`innen entspringen müsse. ${ }^{167}$ Wie kam Langenbucher zu dieser rassistisch heroisierenden Literaturtheorie, in der er die Beziehung zwischen „Dichtung“ und „Volk“ als eine nationalsozialistische Literaturkultur deutete? ${ }^{168}$ Dies geschah einerseits mit Bezug auf Erwin Guido Kolbenheyers (1878-1962) Rede „Lebenswert und Lebenswirkung der

166 Hitler 1935, 8.

167 Vgl. Langenbucher 1933, 21.

168 Mehr zur NS-Literaturpolitik und NS-Literaturtheorie vgl. Barbian 2010, vgl. Gehler 2010, $23-33$. 
Dichtkunst in einem Volke“ (1932) ${ }^{169}$, die 1933 im Sammelband „Des deutschen Dichters Sendung in der Gegenwart“ vom Theaterwissenschaftler Heinz Kindermann (1894-1985) herausgegeben wurde. ${ }^{170}$ Andererseits verwies Langenbucher auf den Begriff des „Volkes“ bei Wilhelm Stapel (1882-1954) in „Volkstümliche Erziehung“ (1917). ${ }^{171}$ Aus diesen Referenzen leitete Langenbucher folgende Definition für die „Volkshaftigkeit“ und „deutsche Dichtung“ ab:

„[...] volkshaft [darf] nur die Dichtung genannt werden [...] die blutmäßig aus dem wirklichen Lebensgrunde eines Volkes herauswachse und deren Schöpfer mit Millionen anderen ein Glied sei in der von uns Volk genannten Menschen- und Schicksalsgemeinschaft. [...] deutsch sei nur der Dichter, der unseres Blutes und Mitträger unseres Schicksals sei, und deutsch sei nur die Dichtung, aus der wir Stimmen unseres Blutes und die Sprache unseres Schicksals hören." ${ }^{172}$

Zu den Aufgaben eines solchen „deutschen“ „Dichters“, der „blutmäßig“ seinem „Volk“ angehören müsste, gehörten:

„[...] den heldischen Grundzug im Wesen des deutschen Volkes zu erspüren, künstlerisch zu veranschaulichen und dem Volk zu lebendigem Bewusstsein zu bringen. Wir wollen es nie vergessen, der heldische Gedanke ist der große Machtgedanke der deutschen Geschichte, wobei Macht [...] lediglich in Selbstbetrachtung, Selbstreue und Selbsterfüllung [...], schon geweckten und noch ungeweckten in uns ruhenden Lebenskräfte bedeutet, also im tiefsten Sinn nicht Herrschaft über andere, sondern über uns selbst als einzelne Deutsche und uns selbst als Volk oder anders gewendet: Herrschaft über unser einzelnes und unser gemeinsames Schicksal." ${ }^{\text {173 }}$

Die „Volkshaftigkeit“ in der nationalsozialistischen „Dichtung“ sei die Darstellung ihrer vermeintlichen „Schicksalserfülltheit“. ${ }^{174}$ Wenn man Langenbuchers Gedankengang folgen will, dann war die „deutsche Dichtung“ eine literarische Darstellung der Herrschaft über die „Schicksalsmächte des Erfolges“, wie es der Leitsatz des Glücksratgebers von C.H. Huter proklamierte.

Inwiefern lassen sich Langenbuchers Kriterien einer rassistischen „Dichtung“ auf Fabers Erlebnisroman anwenden? Wie stand es bei Faber um die „Volkshaftigkeit“ und die Darstellung des „heldischen Gedanken[s]“ einer „völkischen“

169 Vgl. Kolbenheyer 1932.

170 Vgl. Kolbenheyer 1933a. Mehr zur NS-Theaterpolitik und NS-Theatertheorie s. Kap. 15 u. 16. 171 Langenbucher verwies auf die 3. Aufl. von 1928, vgl. Stapel 1928, 28. Vgl. Langenbucher 1933, 19, Fussnote 2.

172 Langenbucher 1933, $20 \mathrm{f}$.

173 Ebd., $21 \mathrm{f}$.

174 Vgl. ebd., 22. 
„Schicksalserfülltheit“? Faber entwarf in seinem autobiografischen Erlebnisroman stereotypisierte Handlungsmuster einer nationalsozialistischen Lebensführung. Diese sollten der Leserschaft die „Schicksalserfülltheit“ einer rassistischbiologistisch gelebten, emotional-körperlich erfahrbaren ,Glückskultur` vorspielen. Faber machte keinen Hehl daraus, dass er der NS-Ideologie vollkommen hörig war und „des deutschen Dichters Sendung “ ${ }^{175}$, im opferbereiten Dienst an der „Volksgemeinschaft“ zu wirken, als ehrenvoll genug ansah, um dabei „Glück“ zu empfinden, wie es Ley verlangte. ${ }^{176}$ Dieses vaterländische Ehrgefühl stellte der Autor gleich an den Anfang seines Romans, indem er ein Zitat Oberst Konstantin Hierls (1875-1955), Staatssekretär im „Reichsarbeitsministeriums“ und späterer „Reichsarbeitsführer“, anführte: „Jeder uneigennützige Dienst am Volk ist Ehrendienst“. ${ }^{177}$

\subsection{Visualisiertes „Glück“: Die propagandistische Bildsprache der Erlebnisromane}

Neben den Narrativen der Erlebnisromane lassen sich auch die Bildsprachen der beiden Erlebnisromane vergleichen. Sowohl auf ikonografischer als auch ikonologischer Analyseebene sind die Bucheinbände und abgebildeten Zeichnungen der Erlebnisromane aufschlussreich. Das Buchcover von Fabers Erlebnisroman (Abb. 10) zeigt im Vordergrund einen „glücklich“ strahlenden jungen Mann mit blonden Haaren und nacktem, muskulösem Oberkörper, der die Romanfigur Paul porträtiert. Mit der rechten Hand grüßt er fröhlich die Betrachter*innen, während er mit der linken Hand einen Spaten hält. Im Hintergrund arbeitet eine anonyme Masse von jungen Männern, welche dasselbe Erscheinungsbild wie Paul abgeben. Gemeinsam symbolisieren sie die visuelle Entindividualisierung der leistungsorientierten Einheit der „Volksgenossen“ im „Arbeitsdienst“. Die Sicherstellung einer unmissverständlichen Bildsprache, welche die propagandistische Bildbotschaft transportierte, war im Interesse des Verlags und der NS-Literaturpolitik. Faber stellte die Buchillustrationen mit Tusche her.

In Tasches Erlebnisroman sind sowohl Buchcover (Abb. 8) als auch Zeichnungen von Heinz Gerster, einem professionellen Illustrator, geschaffen, der auch in der Nachkriegszeit seine Arbeiten veröffentlichen konnte. ${ }^{178}$ Seine Zeichnungen illustrieren, mit Hilfe einer reduzierten Strich- und Linienzeichnungstechnik, die

175 Vgl. ebd., 20, Fussnote 3.

176 Vgl. Ley 1939, $257 \mathrm{f}$.

177 Vgl. Faber 1934, [7].

178 Vgl. Bach 1955. 
Heim- und Hofarbeit im „Arbeitsdienstlager“. Gerster zeichnet ,glücklich“ wirkende Frauen, strahlend und singend, in der Küche beim Kartoffelschälen oder beim Schweinefüttern. Im Verbund mit unterschiedlichen Abbildungen vom Unterhaltungs- und Abendprogramm, beim gemeinsamen Singen, Laientheaterspiel, Tanz und Musizieren propagiert der Zeichner ein stilisiertes Alltagsbild im Sinn des nationalsozialistischen Ideals der „Deutschen Kunst“. ${ }^{179}$ Der Standpunkt des Zeichners ist ein verklärter Blick auf das wegen seiner natürlichen Einfachheit scheinbar ,glückliche“ Landleben. Das Buchcover (Abb. 8) zeigt exemplarisch eine ,überglücklich“ wirkende Christine beim „Arbeitsdienst“. Die propagandistische Bildwirkung sollte womöglich bei der Leserschaft des Erlebnisromans die Sehnsucht nach gemeinschaftsstiftender Zugehörigkeit zum „Arbeitsdienst“ erwecken und sie zur Teilnahme mobilisieren.

Mit welchen sprachlichen Mitteln setzt sich die nationalsozialistische Bildästhetik in Tasches Beschreibungen weiter fort? Die Abbildungen sind illustrative Ergänzungen zur Erzählung von Christines Empfindungen und Erlebnissen. Tasche verwendet passagenweise einen symbolistisch überhöhten Sprachstil, der in seiner Metaphorik an christliche Paradiesvorstellungen oder an die biedermeierlichen „Idyll“-Beschreibungen des ,kleinen Glücks im Winkel“ erinnert, jedoch mangels Ironie und literarischen Erzählvermögens nicht dieselbe Ausdruckskraft entwickelt. Diese wissenshistorische Rückbesinnung, insbesondere an die literarische Biedermeier Zeit (1815-1848), war ebenfalls ein ästhetisches Theoriekonzept der NS-Literaturpolitik. Je stärker die Aufrüstungspolitik und die Kriegsszenarien des Zweiten Weltkriegs an die Zivilbevölkerung heranrückten, umso wichtiger erschien es der Kulturpropaganda, sich in der Literatur, Kunst, Musik und im Theater auf die angeblich unverwüstbare harmonische Welt des „Dritten Reiches“ und deren ruhiges, friedvolles und „glückliches“ Landleben zurückzubesinnen.

Welche emotionspolitische Aufgabe übernehmen die Abbildungen in den Erlebnisromanen? Die Illustrationen fangen die in Worte gefassten Eindrücke und Gefühlszustände, beispielsweise bei Christines Ankunft am Einsatzort, ein. Sie dienen zur visuellen Verdoppelung der emotionspolitischen Botschaft der Autor^innen, indem sie den „emotives“ (Gefühlswörtern) ikonografischen und ikonologischen Ausdruck verleihen: „Dort ist ein Fleckchen Erde, das in seiner Unberührtheit noch den Reiz des 16. Jahrhunderts trägt, nicht übertüncht von grauer

179 Die „Deutsche Kunst“ wurde in Abgrenzung zur „entarteten Kunst“ der expressionistischen Moderne von der NS-Kulturpolitik propagiert. Formal schuf sie jedoch keinen ,neuen Kunststil. Mehr zur Kunst im NS-Regime vgl. u. a. Zuschlag 1995, Benz, Eckel und Nachama 2015. 
Zivilisation: ein Fleckchen Erde - schön wie die leuchtende Sonne, hell wie der Quell, der lustig klingend vom Berge springt.“180

\subsection{Fazit}

Abschließend stellt sich die Frage, wie erfolgreich die Gefühlspolitik solcher Erlebnisromane war? Konnte sich die Begeisterung für den „Arbeitsdienst“ auf das junge Zielpublikum übertragen? Eine pragmatische Antwort auf diese Frage wird mit Blick auf den „weiblichen Arbeitsdienst“ und dessen arbeitspolitischen Kontext im NS-Regime gegeben.

Im Herbst 1933, als Lisa Tasche ihren „Arbeitsdienst“ antrat, geschah dieser Einsatz noch auf freiwilliger Basis. Sie stellte ein Gesuch und hoffte auf baldige Antwort von der entsprechenden Dienststelle. Per 21. Februar 1938 wurde jedoch ein „Pflichtjahr“ für junge Frauen eingeführt. Dies betraf all jene arbeitssuchenden Frauen, die im Sinn hatten, entweder in der Textil-, Bekleidungs-, Tabakindustrie oder als kaufmännische Angestellte oder Bürohilfskraft eine Stelle zu finden oder die bereits in diesem Bereich tätig waren. ${ }^{181}$ Mit dem Ausbruch des Zweiten Weltkriegs wurde der bisher freiwillig geleistete „NS-Arbeitsdienst“ für junge, ledige Frauen zwischen 17 und 25 Jahren, „die nicht voll berufstätig sind, nicht in beruflicher oder schulischer Ausbildung stehen und nicht als mithelfende Familienangehörige oder in der Landwirtschaft dringend benötigt werden“ zur Pflicht. ${ }^{182}$ Das propagandistische Ziel dieser „Hochschule nationalsozialistischer Erziehung“183 war es, junge Frauen als Hausgehilfinnen in der Land- und Hauswirtschaft einzusetzen, um „vorindustrielle Sozialbeziehungen innerhalb eines industriellen Systems zu rekonstruieren“184. Hinter diesem ökonomisch ineffizienten Konzept stand die arbeitsideologische Absicht, die „Volksgenossinnen“ mittels gezielter Einübung und Schulung von Ritualen und Verhaltensnormen des „Deutschen Frauenarbeitsdiensts“ lückenlos in die „Volksgemeinschaft“ einzugliedern. ${ }^{185}$ Die Frage, ob sich viele Freiwillige für den „Arbeitsdienst“ aufgrund der Lektüre der autobiografischen Erlebnisromane rekrutieren ließen, wird spä-

180 Vgl. Tasche 1935, 11.

181 Vgl. Bajohr 1980, 349.

182 §2 der VO über die Durchführung der „Reichsarbeitsdienstpflicht“ vom 04.09.1939 (RGBl. I, S.1693) zit. nach Bajohr 1980, 351.

183 Vgl. Hierl, Konstantin. 1941. Ausgewählte Schriften und Reden, Bd. 2. München: Eher, 249 zit. nach Bajohr 1980, 340.

184 Vgl. Bajohr 1980, 341.

185 Vgl. ebd., 342. 
testens mit der gesetzlichen Regelung obsolet. Dennoch waren die autobiografischen Erlebnisromane propagandistische Werbeträger für den „Arbeitsdienst“. Mit ihren emotionspolitischen Darstellungen einer praktizierten Selbsterziehung zur nationalsozialistischen Lebensführung sind sie mit den Anleitungen von Glücksratgebern durchaus vergleichbar und stellen folglich ein weiteres Phänomen einer affirmativen Gefühlspolitik dar.

Ein Hinweis für die langjährige Verbreitung von Tasches Erlebnisroman ist die Widmung im Exemplar, welches für die vorliegende Analyse verwendet wurde: „Der Siegerin im Wettbewerb beim Betriebssport. 24.8.41 Gertrud [Tutzmeier?]. Gewidmet von der Papierfabrik Scheufelen“186.

Beim Vergleich der beiden Erlebnisromane ist der Quellenwert zur Analyse einer Politik der ,Glückskulturen“ ersichtlich. Die Autobiograf^innen stellen in den Aufbaujahren des NS-Regimes existentielle Fragen zur nationalsozialistischen Lebensführung: Wie soll eine NS-ideologische „Gemeinschaft“ gebildet werden? Wer gehört emotionspolitisch und „rassenideologisch“ dazu und wer ist davon ausgeschlossen? Wie lässt sich die soziale Kluft zwischen Intellektuellen und Arbeiter^innen schließen? Wer soll welche Aufgabe im totalitären Gesellschaftssystem übernehmen? Zu welchem Zeitpunkt ist jemand „Führerin“, wann ist jemand „Dienerin“ und ab wann Opfer? Worin besteht der Unterschied zwischen glauben, denken, fühlen, wollen und handeln? Soll die „Rassenmoral“ die christliche Moral ersetzen? Wie kann das ideologische Gemeinschaftsgefühl gestärkt werden? Wie kann ich „Kraft durch Freude“ schöpfen? Wie können wir das „Glück“ erzwingen?

In den Erzählungen werden die emotionspolitischen Entwicklungen der Haupt- und Nebenfiguren in Gesprächen zwischen den „Kameradinnen“ bottom up subtil verhandelt oder in Vorträgen top down dogmatisch gelehrt. Intellektualität und Intellektuelle, als ein bürgerlicher Habitus und Typus, werden gemäß der NS-Dichtungstheorie als „snobbistische[...] oder brutal-ironische[...] ,Gesellschafts'-Darstellungen“ verpönt. ${ }^{187}$ Im Gegensatz dazu wird Fühlen zur emotionspolitischen Prämisse erhoben: das „Rassengefühl“ könne intellektuell nicht erfasst werden, so Dr. Burg, sondern die „Volksgenossinnen“ müssten daran glauben, indem sie es fühlten.

Diese emotionspolitische Ideologie macht zu Beginn der Erzählungen vor allem den weiblichen Arbeitsdiensttätigen und einigen männlichen Studenten zu

186 Die Papierfabrik Scheufelen in Lenningen wurde 1855 gegründet und existierte bis April 2018. Die Scheufelen GmbH wurde per Februar 2019 insolvent und wird als „Silphie Paper GmbH“ weitergeführt, http://silphiepaper.com/, 02.11.2020.

187 Vgl. Nachwort des Herausgebers. In: Kindermann 1933, 265-283, 283. 
schaffen. Von dem Moment an, in welchem sie durch autosuggestive „Selbsterkenntnis“188, wie es C.H. Huter nennt, ihre persönlichen Fähigkeiten zum Erlangen der Position als „Führerinnen“ erkennen und die ,Rolle“ der „Dienerinnen“ abstreifen, blühen sie auf und werden zu den größten Ideolog^innen des Arbeitsdienstlagers. Sie werden für den Dienst der propagandistischen Freizeitgestaltung eingesetzt und treten als ideologische Redner*innen auf. Leistungsorientiert entwickeln sich die jungen Menschen zu „Erzieherinnen“ gemäß der arbeitsideologischen NS-Doppelrolle. ${ }^{189}$

Die Erlebnisromane zeichnen ein emotionspolitisches Psychogramm der „Volksgemeinschaft“ im Mikrokosmos der „Arbeitsdienstlager“. Gebetsmühlenartig werden die ideologischen Glaubenssätze für die Leserschaft wiederholt, als würden sie durch ihre Repetition an Evidenzwert gewinnen. Überwachung, Bestrafung und Förderung als erzieherisch-disziplinarische Maßnahmen gehen nicht nur von den Lagerleiter*innen aus. Alle beobachten einander. Die Protagonist*innen nutzen psychotechnische Methoden der „Erfolgs-Psychologie“190 zur leistungsorientierten „Menschenbeurteilungskunst“191, im Sinne C.H. Huters, indem sie nach charakterologischen und psycho-physiognomischen Merkmalen Ausschau halten.

Das Ziel dieser sozial- und emotionspolitischen Überwachungspraktik ist, das Gegenüber rascher durchschauen zu können, damit dessen Handeln antizipiert und gegebenenfalls unterbunden werden kann, um die kollektive „Leistungs-Steigerung“"192 nicht zu gefährden. Während der arbeitspsychologischen Observierungsprozesse misstrauen sich die Arbeitsdienstverrichtenden selbst am meisten. Denn sie wissen um die Fragilität ihrer ideologischen Gesinnung, wie sich bei Christine zeigt. Sie wissen, dass es unmöglich ist, den geforderten „Willen“, die „Kraft“ und die „Freude“ zur Erzwingung eines totalitären „Glücks“ aufzubringen. Die körperlichen Entbehrungen und repetitiven Arbeiten sind hart und kräftezehrend. Aus diesem Grund sehen sie in ihrem Gegenüber ständig potentielle Verräter`innen und Schwächlinge, die nicht dieselbe aufopfernde „Willenskraft“ aufbringen können, wie sie es sich täglich im Selbsterziehungsprozess einer autosuggestiven Glückspraktik abverlangen.

Die Ambivalenz der nationalsozialistischen Politik einer arbeitspsychologischen Gefühlskultur wird selbst in den von der Partei kontrollierten Erlebnisromanen offensichtlich. Die Autor^innen dokumentieren in ihren Erzählungen ei-

188 Vgl. Huter 1940, 4.

189 Vgl. Decker 1935.

190 Vgl. Huter 1940, 4.

191 Vgl. ebd.

192 Vgl. ebd. 
nerseits die hegemonialen Propagandadiskurse. Andererseits stellen sie die zum Teil subtil ablaufenden psychopolitischen Entwicklungsprozesse und massenpsychologischen Mechanismen einer schleichenden ideologischen Unterwanderung dar.

In welchem Zusammenhang trifft man bei der Lektüre auf literarische Darstellungen von Glückswissen? „Glück“ wird in der arbeitsideologischen Gefühlspolitik als anzustrebendes Endziel der nationalsozialistischen Gesellschaftsutopie propagiert. Auf dem Weg dahin entwickle sich „Glück“ bei der Arbeit im kollektiven Handeln und im rassistischen Gemeinschaftsgefühl. Dabei haben ästhetische Elemente, wie der Gemeinschaftsgesang, in welchem die einzelnen Sänger^innen zum kollektivistischen Gesangskörper biologistisch verschmelzen, eine zentrale Bedeutung. Privates „Glück“ in Form von Liebesglück tritt in flüchtigen Begegnungen mit dem anderen Geschlecht auf und wurde als Teil der „rassenhygienischen“ Partnerwahl und Geburtenpolitik gefördert, wie in Kapitel 14 gezeigt wird. Von „Glück“ und „Freude“ berichten die Autobiograf*innen häufig. Sie beschreiben dieses Gefühlswissen mit Hilfe von „emotives“ (z. B. strahlende Augen und Gesichter bei der Arbeit, in der Freizeit, beim Singen und Tanzen oder beim rhythmischen Arbeiten auf der Baustelle). Faber spricht auch von denjenigen, die angeblich kein „Glück“ fühlen, wie zum Beispiel die liberal denkenden Studierenden, welche nur an den Selbstzweck ihrer akademischen Karriere denken und an ihrem Egoismus scheitern. Das „Glück“ der „Volksgemeinschaft“ wird folglich von beiden Autor^innen als die Erfüllung ihrer autosuggestiven Träume gepriesen.

Nach der Lektüre bleiben jedoch Zweifel an der Wahrhaftigkeit der beschriebenen Gefühle. Beide Autor`innen beschreiben, neben ihren ideologischen Bekenntnissen zum Nationalsozialismus, die eigenen oder fremden Zweifel und Unsicherheiten über das Leben im neuen „rassenhygienischen“ Gesellschaftssystem. Darüber hinaus werden Tätlichkeiten, Bestrafungen, Gerüchte von Verhaftungen und Misshandlungen, Kollektivstrafen, mangelhafte Ernährung, Krankheiten und ein Todesfall aufgrund körperlicher Erschöpfung, eine „Bücherverbrennung“ und Rebellion dokumentiert. Selbstredend werden diese Erlebnisse im Rahmen der NSArbeitsmoral von den Autor^innen Tasche und Faber gerechtfertigt bzw. als staatsfeindliches Verhalten diskreditiert. Dennoch stehen die Ereignisse für die Leserschaft im unmittelbaren Kontext zur NS-Arbeitsmoral „Kraft durch Freude“. Angesichts der subjektivistischen und psychologisierenden Sprachstile der Autor^innen decken sie aus heutiger Sicht die Ambivalenz der Politik einer maskierten ,Glückskultur“ im „Arbeitsdienst“ auf.

Die unterschiedlichen Geschlechterperspektiven, aus denen die Autor^innen Tasche und Faber ihre autobiografischen Erlebnisberichte verfasst haben, geben nicht zuletzt Einblick in die Geschlechterstereotypisierung im Nationalsozialismus, die zur „rassenhygienischen“ Gefühlskultur im folgenden Kapitel 14 überleitet. 